\title{
Alternativas para la alimentación de cerdos, Santo Domingo de los Tsáchilas, Ecuador, Diciembre 2008
}

\section{Autores:}

Ing. Diana Cristina Buitrón Marín

Dr. Luís Marcelo Almeida Uraga 


\section{Resumen}

La investigación se realizó en la finca “El Oasis”, ubicada en la provincia de Santo Domingo de los Tsáchilas, cantón Santo Domingo. Se realizaron tres ensayos para evaluar el uso de plátano verde o el tocón de palmito más un suplemento proteico en la alimentación a 15 cerdas gestantes distribuidas al azar en 5 por tratamiento. Se utilizó el Diseño Completo al azar con diferente número de observaciones por tratamiento (DCA), y con la prueba de Tukey al 5\%. Los resultados no presentaron diferencias significativas entre tratamientos; sin embargo, numéricamente T2 (Suplemento proteico + palmito), demostró mejores resultados en incremento de peso post parto y número de lechones al nacimiento. El análisis económico del tratamiento T1 mostró mejor costo de producción (suplemento proteico + plátano) con un costo por cerda de $\$ 182,34$ y una mejor relación beneficio costo (Un valor de \$1.12). El segundo experimento consistió en evaluar la utilización del rechazo de plátano (Musa paradisíaca) ó palmito (Bactris gasipaes) más suplemento proteico en la alimentación de cerdas lactantes junto con utilización de dichos rechazos procesados en forma de harinas como materia prima para la elaboración de dietas iniciales para alimentación de lechones en etapa inicial de 45 días en grupos de 5 animales trasladados a comederos individuales para ser alimentados dos veces al día. Se evaluaron tres tratamientos (T1, T2, T3); se aplicó el Diseño de Bloques Completamente al Azar (DBCA), con un total de 5 repeticiones a cuyos resultados se les aplicó prueba de significación de Tukey al 5 \%. Los resultados mostraron que el incremento de peso evaluado en lechones, a partir del día 1 al 21 de nacidos, estadísticamente no presentó diferencias significativas. Numéricamente el mejor tratamiento fue el T3 con un incremento de $0.21 \mathrm{~kg} /$ día, a partir de los 21 hasta los 45 días de vida influenciado por la alimentación inicial que recibió la camada y la leche de la cerda. Estadísticamente en este período se presentaron diferencias significativas, en donde los mejores tratamientos fueron T1 y T3 con 0.28 y 0.27 kg/día. El peso al destete, numéricamente el T1 obtuvo un peso promedio de lechones de $12.17 \mathrm{~kg}$, La conversión para lechones, evaluada a partir de los 21 días, mostró diferencias estadísticas significativas, particularmente el T1 con $0.46 \mathrm{~kg}$. El porcentaje de mortalidad no tuvo mayor incidencia, ya los valores fueron inferiores al 20\% que indica la teoría. Económicamente el mejor tratamiento correspondió al T2 (plátano) con un costo de producción por lechón destetado de \$37.14 y una relación costo - beneficio de \$1.21. El tercer experimento evaluó en 30 lechones Landrace-Poland (mestizos) con una edad de 45 días, seleccionadas al azar; se probaron dos raciones alimenticias en cerdos: plátano (20\% de la dieta calculado en base seca) + Suplemento proteico y palmito (10\% de la dieta calculado en base seca) + Suplemento proteico con un testigo absoluto, para las fases de crecimiento y acabado. La duración del ensayo fue de 120 días aproximadamente o hasta que el grupo de cada tratamiento alcanzó los 80 kg promedio; cada 15 días se realizaba el pesaje de los animales para aumentar la proporción de la dieta de acuerdo con el peso de los mismos. El plátano y palmito fresco fueron proporcionados en las horas de la mañana y el suplemento proteico en horas de la tarde, así el diseño experimental empleado fue de completos al azar con diferentes números de observaciones por tratamientos (DCA), y la prueba de Tukey al $5 \%$. Se evaluaron las variables, incremento de peso posterior al inicio del ensayo; conversión alimenticia; mortalidad y análisis económico realizado en base al método $A B C$, analizando los costos que varían, costos fijos, interés capital. Los resultados mostraron que la variable incremento de peso el tratamiento T2 (Balanceado comercial), se obtuvo los valores más elevados, en la fase de crecimiento con 0.57 kg/día y en la fase de acabado con 0.86 $\mathrm{kg} /$ día respectivamente. 


\section{Abstract}

The research was conducted in the farm "The Oasis", located in Santo Domingo de los Tsáchilas County , three tests were realized. Evaluation of the consumption of green plantain or about the stump of palm heart and a supplement protein in the feeding to 15 at random pregnant bristles in 5 by a pig handling. It was used the DISEÑO COMPLETO AL AZAR (DCA), with different number of observations by each treatment and with the Tukey's at $5 \%$. The results did not present relevant differences between treatments. Nevertheless, numerically $\mathrm{T}_{2}$ (supplement protein + palm heart), demonstrated better results in the increasing of postnatal weight and number of baby pigs to the birth. The economic analysis of treatment T1 showed to better production cost (supplement protein + plantain) with a bristle pig’s price of about $\$ 182.34$ and a better prize benefit relation (\$1.12). The second experiment, to evaluate the use of the waste of plantain (musa paradisiacal) or palm heart (bactris gassipaes) plus protein supplement in the feeding of nursing bristles, but the use of these rejections processed waste in flours variety, as raw material for the elaboration of diets initiates to them for feeding of pigs in initial stage of 45 days in groups of 5 animals, transferred to individual feeders to be fed twice the day. Three treatments were evaluated (T1, T2, T3). IT was applied The DISEÑO DE BLOQUES COMPLETAMENTE AL AZAR (DBCA), with a total of 5 repetitions on those results there was applied a test of meaning Tukey was applied to them to $5 \%$. The results showed that the increase of weight evaluated in pigs, from the first to the 21 days they were born, statistically did not present relevant differences. Numerically the best treatment was the T3 with an increase of $0,21 \mathrm{~kg} / \mathrm{a}$ day, from the 21 until the 45 days of life influenced by the initial feeding that received the litter and the milk of the bristle. Statistically in this period they presented significant differences, where the best treatments were T1 AND T3 with 0,28 and $0.27 \mathrm{~kg}$. The weight to the weaning, numerically the T1 obtained a pig' s average weight of $12,17 \mathrm{~kg}$. The conversion for pigs, evaluated since they were 21 days old , showed relevant statistical differences, particularly the T1 with $0.46 \mathrm{~kg}$. The percentage of mortality did not have major incidence, the amounts were less than $20 \%$ as the theory shows. Economically the best treatment belonged to the T2 (plantain) with a cost production of $\$ 37,14$ each piglet and a relation cost-benefit from $\$ 1,21$. The third experiment evaluated in 30 Landrace-Poland pigs (mestizos) of 45 days old, selected at random. Two food portions were tried in pigs : plantain ( $20 \%$ of the estimated diet in dry base) + I supplement protein and palm heart (10\% of the estimated diet in dry base) + I supplement protein with an absolute witness, for the phases of growth and finished. The duration of the test was of 120 days approximately or until the group of each treatment reached 8okg average. Every 15 days the animal weight was realized to increase the diet amount in agreement with the weight of the same. The plantain and fresh palm heart were provided in the in the morning hours and the supplement protein in the afternoon. The experimental design used was absolutely at random with different numbers of observations by treatments (DCA), and the Tukey's test to $5 \%$. The variables were evaluated, increase of weight subsequent to the beginning of the test; nutritional conversion; mortality and economic analysis realized on the basis of the $A B C$ method, analyzing the costs that vary, fixed costs, capital interest. The results showed that the different increase of weight, the T2 treatment (balanced commercial), was obtained from the highest values, in the phase of growth with $0,57 \mathrm{~kg} / \mathrm{a}$ day and in the finished phase of with $0,86 \mathrm{~kg} / \mathrm{a}$ day respectively. 


\section{Introducción}

La creciente demanda de alimentos a nivel mundial hace que el cerdo doméstico (Sus scrofa domestica) sea criado con la única finalidad de producir carne, dado que a esta especie es considerada una fuente de proteína de alta calidad.

Según estimaciones de la FAO, la porcicultura es una de las actividades que más desarrollo ha alcanzado entre las industrias pecuarias, vemos como en el año 2002 llegó a una producción de 80 millones de toneladas de carne que representaba un 40\% de toda la producción a nivel mundial; destacándose Asia, Europa y Norteamérica con más del $85 \%$ de la producción mundial. Es pertinente mencionar que los países de América del Sur obtuvieron una producción de 2,5 millones de toneladas de carne de cerdo en este mismo período.

En el Ecuador la porcicultura es una labor pecuaria que se realiza en todo el país; sin embargo según el SICA (Servicio de Información Agropecuaria del Ministerio de Agricultura y Ganadería) esta actividad está poco desarrollada, debido a que más del 80\% de la producción nacional realiza una explotación de tipo casero y tan solo la diferencia de este porcentaje se logra en granjas tecnificadas, este factor conlleva a que la oferta y la calidad sean deficientes.

La situación anterior sustenta la necesidad de impulsar la investigación para encontrar soluciones factibles en este sector. De no lograrse, la tendencia de satisfacer la demanda tecnológica de la actividad porcícola industrial intensiva que representa el $20 \%$ que cuenta con el apoyo de técnicos pecuarios será imposible ya que el restante $80 \%$ no lo tiene.

En cuanto a la utilización de la tierra, ésta es mixta, en aquellas que se prioriza la agricultura o la ganadería bovina, como actividad secundaria y de género siempre existe porcinos, además de recursos que son utilizados pero sin criterio técnico, como el suero de la leche resultado de la actividad quesera, el rechazo de banano, de plátano, de malanga, de palmito, de yuca, de exportación; productos de finca como la fruta de pan, caña de azúcar y algunas plantas forrajeras que ayudarían eficientemente al reemplazo parcial de productos estacionales como el maíz, el polvillo de arroz y otros que son acaparados por la industria avícola monopólica, de gran capacidad de almacenaje y que además manejan paralelamente el negocio de balanceados.

Planteado el problema, cabe indicar que éste es una de las responsabilidades que se considera corresponde a la Universidad: presentar soluciones y cumplir con su mandato social. Par lograrlo se requiere impulsar programas o proyectos de extensión-investigaciónextensión como una de las alternativas, en consideración a que por un lado la investigación presenta soluciones y por otro la extensión permite su socialización.

En la actualidad diferentes institutos de investigaciones agropecuarias como Universidades e instituciones privadas, se han volcado hacia la búsqueda de fuentes alternas de energía, proteína y minerales no tradicionales y de producción nacional, con el objetivo de sustituir al máximo posible el porcentaje de inclusión de maíz y soya, disminuyendo los costos de producción y la dependencia.

Para lograr el objetivo propuesto se ha promovido el uso de residuos de cosechas, arroz, cáscara de maracuyá, plátano, palmito, lodo de palma, excretas, bacterias fermentadoras, subproductos del maíz y de pescado, entre otros.

Hoy en día se ha pensado utilizar no solo el desperdicio del plátano, sino también residuos foliares en la alimentación de los cerdos. En cuanto al palmito en realidad no se conoce de la existencia de investigación alguna que permita determinar la efectividad de este producto en la alimentación en cerdos por lo que un estudio en este ámbito se hace indispensable. 


\section{Materiales, Métodos y Procedimientos}

\section{Etapa de Gestación}

- Factores en estudio.

- Suplemento proteico + Plátano

- Suplemento proteico + Palmito

- Balanceado comercial

- Tratamientos evaluados.

Los tratamientos evaluados fueron un suplemento proteico más dos materiales disponibles en la zona como son el plátano barraganete y el palmito, además se utilizó un testigo absoluto (Balanceado comercial). Las comparaciones correspondientes se presentan en el siguiente cuadro.

\section{Cuadro No 1}

Tratamientos evaluados en la investigación del uso de plátano o palmito frescos más suplemento proteico en alimentación de cerdas gestantes Santo Domingo, 2007.

\begin{tabular}{cl}
\hline SIMBOLOGIA & \multicolumn{1}{c}{ TRATAMIENTOS } \\
\hline \hline T1 & F1átano 5 kg + 700 g de suplemento protrico 30\% \\
T2 & Palmito 5 kg + 950 g de suplemento proteico 30\% \\
T3 & Testigo_Balanceado Comercial \\
\hline
\end{tabular}

La composición y análisis calculados de las dietas experimentales para el estudio, de dos raciones con productos convencionales en cerdas gestantes, se detallan en los siguientes cuadros:
Cuadro No. 2

Composición del Concentrado utilizado en la investigación del uso de palmito fresco más suplemento proteico en alimentación de cerdas gestantes Santo Domingo, 2007.

\begin{tabular}{lc} 
Materia Prima & Porcentajes \% \\
\hline \hline Maíz & 28,5 \\
Soya & 31 \\
Pescado & 18 \\
Melaza & 10 \\
Palmiste & 10 \\
Pre-mezcla & 2,5 \\
\hline
\end{tabular}

Fuente: Investigación de campo

\section{Cuadro No 3}

Composición del Concentrado utilizando utilizado en la investigación del uso de plátano fresco más suplemento proteico en alimentación de cerdas gestantes Santo Domingo, 2007.

\begin{tabular}{lc}
\hline Materia Prima & Porcentajes \% \\
\hline \hline Maíz & 27,5 \\
Soya & 19,5 \\
Pescado & 30,5 \\
Melaza & 10 \\
Palmiste & 10 \\
Pre-mezcla & 2,5 \\
\hline
\end{tabular}

Fuente: Investigación de campo

\section{Cuadro No 4}

Composición de pre mezcla utilizada en las dietas experimentales en la investigación del uso de plátano o palmito frescos más suplemento proteico en alimentación de cerdas gestantes Santo Domingo, 2007.

\begin{tabular}{lc}
\hline \multicolumn{2}{c}{ INGREDIENTES } \\
\hline \hline Núcleo & $100 \mathrm{~g}$ \\
Sal & $500 \mathrm{~g}$ \\
Maíz & $1900 \mathrm{~g}$ \\
\hline
\end{tabular}


- Características de las unidades experimentales.

\section{Gestación}

- Número de unidades experimentales: 15 cerdas

- Raza: Landrace- Poland (mestizos)

\section{Características del ensayo}

- Número de tratamientos: 03

- Número de unidades experimentales / tratamiento: 05

- Área útil del experimento: $51,15 \mathrm{~m} 2$

- Dimensiones de la porqueriza: $5,50 \mathrm{~m}$ (largo) $\times 3,10$ $\mathrm{m}$ (ancho)

- Área total de cada porqueriza: $17,05 \mathrm{~m} 2$

\section{Diseño Experimental.}

Se utilizó un DCA (Diseño Completos al Azar) con diferente número de observaciones. El análisis de varianza se presenta en el cuadro 5. Se contó con 3 tratamientos, con un total de 15 unidades experimentales. De acuerdo a los resultados obtenidos, se aplicó la prueba de Tukey al 5\%, para establecer la significancia estadística de las medias de los tratamientos evaluados, se determinó además mediante un nivel de confianza equivalente a 0,05 y 0,01; es decir $95 \%$ y $99 \%$ de seguridad, respectivamente, aplicando la correlación ortogonal para las dietas en estudio.

\section{Cuadro No 5}

Esquema del ADEVA que se empleó en el ensayo del uso de plátano o palmito frescos más suplemento proteico en alimentación de cerdas gestantes Santo Domingo, 2007.

\begin{tabular}{lc}
\hline \multicolumn{1}{c}{ FUENTE DE VARIANZA } & GRADOS DE LIBERTAD \\
\hline \hline Total & 14 \\
Tratamientos & 12 \\
Error & 2 \\
\hline
\end{tabular}

Fuente: Investigación de campo

\section{Datos tomados y métodos de evaluación}

\section{- Incremento de peso.}

Este dato se obtuvo pesando las cerdas gestantes al inicio de la gestación, a los 76 días, y a los 110 días; transcurrido el parto se procedió a pesar a las cerdas al primer día post parto. Con los resultados obtenidos indicaron incrementos de 0-110 días teniendo en cuenta el peso inicial y el peso a los 110 días de gestación. Se utilizó una báscula para tomar los pesos correspondientes.

\section{$\Delta$ de $P$ eso $=$ Peso final - Peso inicial}

\section{- Consumo de alimento diario.}

El consumo de alimento fue dado para los tratamientos por una dieta compuesta de plátano o palmito y sus respectivos concentrados, mismos que se suministraron diariamente y se registraron las cantidades de consumo y desperdicio en gramos.

\section{- $\quad$ Peso y número de lechones al nacimiento.}

Para la variable peso de lechones al nacimiento se procedió a contar los nacidos vivos y a tomar los pesos de los cerditos el día del nacimiento en una balanza gramera de forma individual los cuales fueron registrados. Durante la investigación se presentó incidencia de parvovirus, por lo cual, se procedió a eliminar las observaciones experimentales afectadas, sin que estadísticamente esto causare modifica- 
ciones en los resultados.

\section{- Conversión alimenticia.}

De los datos obtenidos en el consumo de alimento diario, se obtuvo el consumo de alimento en materia seca durante la etapa de gestación de o a 110 días, el cual se lo dividió para el incremento de peso de o a 110 días de la cerda gestantes, aplicando la siguiente fórmula para así obtener la conversión alimenticia:

\section{Consumo TOTAL de alimento}

\section{CA.=}

\section{Incremento TOTAL de peso}

\section{Análisis Económico.}

El análisis económico se determinó mediante el método del $A B C$ en función de costos e índices de producción promedios obtenidos, con las siguientes características de producción, manejo y requerimientos:

- Instalaciones

- Electricidad

- Alimentación

- Sanidad animal

- Mano de obra

- Equipo sin motor

- Equipo con motor

- Costo de la cerda

- Interés de capital invertido

\section{Manejo del experimento}

\section{- Sorteo de las cerdas.}

Como primera actividad a realizar en la implementación fue el sorteo de las cerdas en los tratamientos a evaluar para así obtener a qué tipo de alimentación se someterían, el cual se lo realizó según la incorporación de las cerdas al ensayo.

\section{- Manejo Sanitario.}

En los primeros días de monta de la cerda se realizó una desparasitación con fenbendazol para la eliminación de parásitos internos e ivermectina para el control de parásitos externos y una segunda aplicación a mediados de la gestación, según el peso de las cerdas y las indicaciones del producto.

Quince días antes de la fecha de parto se procedió a vacunar con sus respectivas dosis a las cerdas, las cuales se manejaban en el programa porcino de la granja.

\section{○ Triple.- $5 \mathrm{ml} /$ cerda}

○ Micoplasma.- 2ml/cerda

\section{- Cálculo de dietas}

Las dietas fueron calculadas por el método del tanteo y cuadrado de "Pearson", donde las dosis de los subproductos más concentrado se basaron en los requerimientos nutricionales de la cerda (Anexo 3) y análisis bromatológicos de los subproductos utilizados en la investigación (Anexos 10 y 11). El cálculo de dietas se inicio con el aporte de materia seca y proteína de los subproductos, para luego compensar el faltante mediante el uso de un concentrado, satisfaciendo así los requerimientos nutricionales de las cerdas gestantes.

Como resultado se obtuvo dietas balanceadas de $5 \mathrm{~kg}$ de plátano más 700 gr de concentrado al 30\% de proteína y $10 \mathrm{~kg}$ de palmito más 950 gr de concentrado al 27,9\% de proteína. 
La composición y análisis calculados de las dietas experimentales para el estudio, de dos raciones con productos convencionales en cerdas gestantes, se detallan en los siguientes cuadros:

\section{Cuadro No 6}

Composición del concentrado utilizado en la investigación del uso de palmito fresco más suplemento proteico en alimentación de cerdas gestantes Santo Domingo, 2007.

\begin{tabular}{lc}
\hline Materia Prima & Porcentajes \% \\
\hline \hline Maíz & 28,5 \\
Soya & 31 \\
Pescado & 18 \\
Melaza & 10 \\
Palmiste & 10 \\
Pre-mezcla & 2,5 \\
\hline
\end{tabular}

Fuente: Investigación de campo

\section{Cuadro No 7}

Composición del Concentrado utilizando utilizado en la investigación del uso de plátano fresco más suplemento proteico en alimentación de cerdas gestantes Santo Domingo, 2007.

\begin{tabular}{lc}
\hline \multicolumn{1}{c}{ Materia Prima } & Porcentajes \% \\
\hline \hline Maíz & 27,5 \\
Soya & 19,5 \\
Pescado & 30,5 \\
Melaza & 10 \\
Palmiste & 10 \\
Pre-mezcla & 2,5 \\
\hline
\end{tabular}

Fuente: Investigación de campo

\section{Cuadro No 8}

Composición de pre mezcla utilizada en las dietas experimentales en la investigación del uso de plátano o palmito frescos más suplemento proteico en alimentación de cerdas gestantes Santo Domingo, 2007.

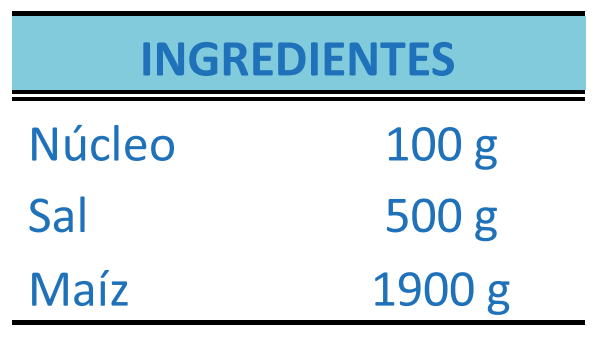

Fuente: Investigación de campo

\section{- Alimentación.}

Ingresadas las cerdas al ensayo se suministró el alimento, el consumo se lo realizó de forma individual, en donde las cerdas tenían que salir de sus corrales a comederos individuales, consumir el alimento y retornar a sus respectivos corrales. Los animales en el día hacían dos salidas, en la mañana para consumir el subproducto y en horas de la tarde para consumir el concentrado. Lo suministrado y el sobrante se pesaron y se registraron diariamente.

La dosis a suministrarse para el T1 (plátano más suplemento proteico) fue de $700 \mathrm{~g}$ de suplemento proteico más $5 \mathrm{~kg}$ de subproducto fresco, para el T2 (palmito más suplemento proteico) fue de 950 $\mathrm{g}$ de suplemento proteico más $10 \mathrm{~kg}$ de subproducto fresco y $2 \mathrm{~kg}$ de balanceado comercial para el tratamiento T3 (testigo).

\section{- Desinfección de corrales.}

Se procedió a realizar una desinfección y lavado total de las instalaciones con la ayuda de cepillo y cloro en una bomba de mochila para toda la instalación con el propósito de remover la suciedad adheridas en las paredes de los corrales y al siguiente día una desinfección con creso a razón de 10 cc/10 I de agua.

Una vez preparadas las instalaciones se procedió a pasar a las cerdas las cuales fueron sometidas con anterioridad a un sorteo, a los 
corrales de gestación, previo un baño de las cerdas con agua y jabón con el propósito de evitar ectoparásitos.

\section{- Traslado a la sala de maternidad.}

A los 110 días de gestación de la cerda, se procedió a realizar el ultimo peso en la fase de gestación y se trasladó a su respectiva sala de maternidad, las mismas que se encontraban lavadas y desinfectadas con yodo en similar dosis a la antes descrita, para así brindar a la madre en ambiente más saludable, labor que se realizó en el momento del traslado hasta el del parto.

- Parto.

Teniendo en cuenta la fecha aproximada de parto se atendieron todos los nacimientos, los cuales en su mayoría fueron en la noche. El manejo se lo realizó igual en todo los tratamientos como fueron: limpieza de membranas, corte y desinfección de ombligo el cual se lo hizo con un compuesto de fenol y violeta de genciana y la aplicación de hierro de $1 \mathrm{ml}$ vía intramuscular por lechón debido a la deficiencia que presentan al nacimiento, posteriormente los cerditos fueron pesados en una balanza gramera de forma individual. Al siguiente día se registro el peso al primer día posparto de la cerda en una báscula en kilogramos.

\section{Materiales e Insumos}

\begin{tabular}{|c|c|}
\hline MATERIALES & INSUMOS \\
\hline Kit de limpieza (escobas, pala, cepillos) & Maíz \\
\hline Báscula & Soya \\
\hline Balanza romana & Palmiste \\
\hline Parideras desmontables & Harina de pescado de exportación \\
\hline Comederos & Melaza \\
\hline Mezcladora automática & Sal \\
\hline Sacos & Núcleo \\
\hline Baldes & Creso \\
\hline Bomba para fumigar & Alcohol \\
\hline Jeringas & Fenbendazol \\
\hline Pistola dosificadora & Ivermectina \\
\hline Machete & Vacuna triple \\
\hline \multirow[t]{5}{*}{ Libreta de campo } & Vacuna Mycoplasma \\
\hline & Oxitetraciclina \\
\hline & Prostaglandina \\
\hline & Mata gusanos \\
\hline & $\begin{array}{l}\text { Jeringas } \\
\text { s. }\end{array}$ \\
\hline
\end{tabular}

\section{Etapa Lactancia}

\section{- Factores de estudio}

- Dieta de lactancia para cerdas + rechazo de plátano

- Dieta de lactancia para cerdas + rechazo de palmito

- Dieta inicial con harina de plátano para lechones

- Dieta inicial con harina de palmito para lechones

- Mortalidad

- Costos

\section{- Variables}

Variables independientes

- Dietas de lactancia para cerdas + rechazos de plátano o palmito

- Dietas iniciales para lechones con harinas de plátano o palmito

\section{Variables dependientes}

- Ganancia de peso en lechones

- Conversión alimenticia en lechones

- Peso de cerdas al final de lactancia

- Mortalidad

- Costos

\section{- Tratamientos evaluados}

Los tratamientos fueron formados aleatoriamente; es decir las cerdas fueron distribuidas en tres grupos de 5 animales al azar, de la siguiente manera: 


\section{Cuadro No 9}

\section{Descripción de los tratamientos evaluados}

\begin{tabular}{|c|l|c|}
\hline Tratamientos & \multicolumn{1}{|c|}{ Descripción } & № de animales \\
\hline T1 & $\begin{array}{l}\text { Concentrado comercial para cerdas (Lactancia) } \\
\text { Concentrado comercial para lechones (Inicial) }\end{array}$ & $\begin{array}{c}5 \text { cerdas con sus } \\
\text { camadas }\end{array}$ \\
\hline T2 & $\begin{array}{l}\text { Dieta para cerdas }+10 \mathrm{~kg} \text { de plátano } \\
\text { Dieta para lechones con harina de plátano }\end{array}$ & $\begin{array}{c}5 \text { cerdas con sus } \\
\text { camadas }\end{array}$ \\
\hline T3 & $\begin{array}{l}\text { Dieta para cerdas }+10 \mathrm{~kg} \text { de palmito } \\
\text { Dieta para lechones con harina de palmito }\end{array}$ & $\begin{array}{c}5 \text { cerdas con sus } \\
\text { camadas }\end{array}$ \\
\hline
\end{tabular}

La composición de las dietas utilizadas para la alimentación de cerdas y lechones en la fase de lactancia, según el tratamiento, se detallan a continuación:

\section{Cuadro No 10}

Composición de las dietas utilizadas en la investigación, para la alimentación de cerdas en lactancia.

\begin{tabular}{|l|c|c|}
\hline \multicolumn{1}{|c|}{ Materia prima } & $\begin{array}{c}\text { Tratamiento } \\
\text { palmito } \\
\text { Cant. (kg) }\end{array}$ & $\begin{array}{c}\text { Tratamiento } \\
\text { plátano } \\
\text { Cant. (kg) }\end{array}$ \\
\hline Maíz & 34,4 & 25,3 \\
\hline Pasta de soya & 13,1 & 17,2 \\
\hline Polvillo de cono & 15,0 & 20,0 \\
\hline Melaza & 10,0 & 10,0 \\
\hline Harina de pescado & 5,0 & 10,0 \\
\hline Palmiste & 20,0 & 15,0 \\
\hline Pre mezcla & 2,5 & 2,5 \\
\hline
\end{tabular}

\section{Cuadro No 11}

Composición de las dietas utilizadas en la investigación, para la alimentación de lechones en lactancia

\begin{tabular}{|l|c|c|}
\hline \multicolumn{1}{|c|}{ Materia prima } & $\begin{array}{c}\text { Tratamiento } \\
\text { palmito } \\
\text { Cant. (kg) }\end{array}$ & $\begin{array}{c}\text { Tratamiento } \\
\text { plátano } \\
\text { Cant. (kg) }\end{array}$ \\
\hline Maíz & 32,5 & 27,3 \\
\hline Pasta de soya & 19,0 & 24,2 \\
\hline Harina de pescado & 10,0 & 10,0 \\
\hline Harinas & $20,0 *$ & $20,0 * *$ \\
\hline Azúcar & 16,0 & 16,0 \\
\hline Pre mezcla & 2,5 & 2,5 \\
\hline
\end{tabular}

* Harina de palmito; ** Harina de plátano

\section{Cuadro No 12}

Composición de la pre mezcla utilizadas en las dietas, para la alimentación de cerdas y lechones en la etapa de lactancia.

\begin{tabular}{|l|c|}
\hline \multicolumn{1}{|c|}{ Materia prima } & Cantidad. (g) \\
\hline Núcleo vitamínico & 100 \\
\hline Sal yodada & 500 \\
\hline Maíz & 1900 \\
\hline
\end{tabular}

\section{- Características de las unidades experimentales}

Número de tratamientos: 3

Número de unidades experimentales / tratamiento: 5 cerdas con su camada

Número de unidades experimentales (total): 15 cerdas con sus respectivas camadas

Raza: Yorkshire 
Edad: cerdas de primer y segundo parto

Camadas: 15 camadas York x Poland ó Duroc

\section{- Características del ensayo}

- Área útil del experimento: 64,05 $\mathrm{m}^{2}$

- $\quad$ Dimensiones del corral de maternidad: 6,10 m (largo) x 2,10 $\mathrm{m}$ (ancho)

- Área total de cada porqueriza: $12,81 \mathrm{~m}^{2}$

\section{Diseño experimental}

Se utilizó un DBCA (Diseño de Bloques Completos al Azar) con diferente número de observaciones, la investigación empleó 3 tratamientos con 5 repeticiones cada uno; el total de unidades experimentales fue de 15 cerdas con sus respectivas camadas. Se realizó comparaciones ortogonales entre tratamientos además se aplicó pruebas de significación Tukey al 5\% de probabilidad.

\section{Cuadro No 13}

Esquema del ADEVA utilizado en la investigación.

\begin{tabular}{|l|c|}
\hline \multicolumn{1}{|c|}{ F de V } & G de L \\
\hline Tratamientos & 14 \\
T1 vs. T2, T3 & 1 \\
T2 vs. T3 & 1 \\
Repetición & 4 \\
Error & 8 \\
TOTAL & 14 \\
\hline$C V=\sqrt{\frac{C M E \exp }{\bar{X}}} \times 100$ & \\
\hline
\end{tabular}

\section{Datos y métodos empleados}

\section{Incremento de peso en lechones}

Para obtener el dato de incremento de peso se registraron durante la evaluación los siguientes datos:

\section{- Peso promedio de lechones al primer día posparto.-}

Un día después del nacimiento los lechones fueron pesados en una balanza, para determinar el peso inicial que presentaron al nacimiento.

\section{- Peso promedio de lechones a los 21 días de edad.-}

Transcurridas las 3 semanas de vida de los lechones, fueron nuevamente pesados para conocer el peso ganado durante ese lapso de tiempo correspondiente a una alimentación estrictamente liquida (leche materna) y dando la pauta para el inicio del suministro de alimento sólido (concentrado).

\section{- Peso promedio de lechones a los 45 días de edad.-}

Cumplido el periodo de lactancia e inicial que estableció la investigación, los lechones fueron pesados y posteriormente destetados, conociendo el peso final con el iniciarían la etapa de crecimiento.

Registrados los datos de pesos correspondientes a lechones se procedió a utilizar la siguiente fórmula para calcular el incremento de peso (kg/día).

$$
\Delta \text { de peso }=\frac{(\text { peso final }- \text { peso inicial })}{\text { Días de evaluación }}
$$

Cabe recalcar que este dato se calculó por periodos comprendidos entre el $1^{\mathrm{er}}-21^{\mathrm{avo}}$ día de nacido y el $21^{\mathrm{avo}}-45^{\mathrm{avo}}$ día de vida de los lechones respectivamente, de esta manera se obtuvo el dato exacto del incremento de peso que cada camada gano durante los primeros periodos de vida.

\section{Peso promedio de cerdas al final de la etapa de lactancia}

Al igual que en lechones se registraron los pesos de las madres en los tres periodos de la investigación, pero para madres no se obtuvo el dato de incremento de peso, debido a que la teoría señala que durante la etapa de lactancia las madres no conseguirán ganar peso, 
debido al desgaste que sufren al amantar a sus crías. De todas maneras estos datos sirvieron para monitorear la pérdida de peso y evitar un desgaste significativo en las cerdas.

El primer peso tomado fue registrado al $1^{\text {er }}$ día posparto, para conocer el estado corporal y peso con el que las cerdas entrarían en la fase de lactancia, cumplidos los 21 días de lactancia, las cerdas fueron pesadas nuevamente para conocer el peso en ese lapso de tiempo y así poder vigilar el desgate que sufrieron por efecto del amamantamiento de la camada en sus primeras tres semanas de vida. Finalmente a los 45 días las cerdas fueron pesadas por última vez para ser destetadas, determinando el desgaste sufrido en la etapa de lactancia, fue importante este dato para poder recomendar acciones complementarias como el flushing para recuperar a la cerda.

\section{- Consumo de alimento}

El dato de consumo de alimento fue registrado necesariamente para realizar el cálculo de conversión alimenticia, además, se registró individualmente las siguientes referencias:

\section{- Consumo promedio de concentrado/cerda.-}

Este dato se obtuvo de la siguiente manera; dividiendo el consumo total de concentrado para los 45 días de evaluación.

C.P. concentrado $/$ cerda $=\underline{\text { Consumo total de concentrado }}$ Días de evaluación

- Consumo promedio de rechazo (plátano - palmito)/cerda.-

De igual manera este dato se obtuvo; dividiendo el consumo total de concentrado para los 45 días de evaluación.

\section{C.P. de rechazo / cerda $=$ Consumo total de rechazo Días de evaluación}

\section{- Consumo promedio de concentrado/camada.-}

Este dato se lo registra a partir del día 21, y se lo obtiene de la sumatoria total de 24 días $(21+24=45)$ de alimentación y se divide para 24.

\section{- Conversión alimenticia}

Para obtener este dato se dividió el consumo de alimento para el incremento de peso, utilizando la siguiente fórmula:

$$
\text { C.A. }=\frac{\text { Consumo de alimento }}{\Delta \text { de peso }}
$$

La finalidad de realizar esta operación es conocer la cantidad de alimento adecuada que se debe suministrar al animal para obtener carne (kg), producto del suministro de dicha cantidad de alimento.

\section{- Mortalidad}

Este dato se obtuvo de acuerdo con el número de lechones muertos por tratamiento, para calcular este parámetro se requirió calcular el número de lechones al destete, a los 45 días de evaluación y consistió en la sumatoria total de lechones destetados por tratamiento. Una vez determinado el total de lechones destetados se aplicó la siguiente fórmula para determinar la mortalidad:

$$
\text { Mortalidad (\%) }=\frac{\text { № total de lechones muertos }}{\text { № total de lechones destetados }} \times 100
$$

\section{Análisis económico}

\section{- Costos de producción}

Para realizar el cálculo de costos de producción se utilizo el método del $A B C$, utilizando la siguiente fórmula: $\mathbf{C T}=\mathbf{X}-\mathbf{P X}$

Donde:

$\mathrm{CT}=$ costo de producción total

$\mathrm{X}=$ costos variables

$\mathrm{PX}=$ costos fijos

Se consideró costos fijos y costos variables, los valores que fueron obtenidos de:

- Mano de obra, 
- Infraestructura,

- Alimentación,

- Servicios básicos,

- Equipo con motor,

- Equipo sin motor,

- Sanidad.

\section{- Beneficio bruto}

Este valor se lo obtuvo del precio de venta por concepto de cada lechón por tratamiento, para el cálculo se aplico la siguiente fórmula: IB $=\mathbf{Y} \times \mathbf{P Y}$

Donde:

$\mathrm{IB}=$ ingreso bruto

$\mathrm{Y}=$ producto

$\mathrm{PY}=$ precio del producto

\section{- Beneficio neto}

El beneficio neto fue calculado mediante la diferencia del beneficio bruto - el coso total por tratamiento, aplicando la siguiente fórmula: $\mathrm{BN}=\mathrm{IB}-\mathrm{CT}$

En donde:

$\mathrm{BN}$ = beneficio neto

$\mathrm{IB}=$ ingreso bruto

$\mathrm{CT}=$ costo total

\section{- Relación costo - beneficio}

Esta variable se determinó con la finalidad de conocer el valor total de aplicar las recomendaciones de la investigación y el beneficio o ingresos económicos que proporcionara la utilización de una de las alternativas que presentan los tratamientos.

Se utilizo la siguiente fórmula: $\quad C B=\frac{B N}{C T}$

En donde:

$\mathrm{CB}=$ relación costo - beneficio

$\mathrm{BN}=$ beneficio neto

$\mathrm{CT}=$ costo total

\section{Manejo del experimento}

\section{Recepción y clasificación de las cerdas}

El proceso se inicio con la recepción de un grupo de madres de raza Yorkshire, las mismas que fueron seleccionadas y clasificadas al azar para la investigación, observando características deseables, tales como:

- Uniformidad en número de pezones (> a 12 pezones).

- $\quad$ Edad y peso adecuado.

Por sorteo los grupos de cerdas quedaron conformados de la siguiente manera:

\section{Cuadro No 14}

Selección y distribución al azar por tratamientos de las cerdas utilizadas en la investigación

\begin{tabular}{|c|l|l|l|l|l|}
\hline Cerda № & Tratamiento & Cerda № & Tratamiento & Cerda № & Tratamiento \\
\hline 102 & Plátano & "Julia" & Palmito & 171 "Yola" & Testigo \\
40 & Plátano & 198 "Karen" & Palmito & 45 "Mery" & Testigo \\
42 & Plátano & 195 & Palmito & 196 & Testigo \\
26 & Plátano & 171 "Yola" & Palmito & "Dolores" & Testigo \\
2 & Plátano & 102 & Palmito & 51 "Flaca" & Testigo \\
\hline
\end{tabular}




\section{- Adecuación de las instalaciones}

El área de maternidad contó con 5 corrales que fueron adecuados con estructura metálica, formando una jaula paridera donde la cerda fue ubicada 10 días antes del parto; en el contorno de los corrales se colocó cortinas con la finalidad de mantener una temperatura adecuada.

Antes de instalar a las cerdas en las parideras, estas instalaciones fueron equipadas con focos calefactores, viruta ó aserrín en el piso para que las madres hagan la cama donde habitaran sus lechones.

Una vez que las cerdas fueron instaladas se sometieron a una alimentación controlada (se disminuyó la dosis diaria de alimento), así mismo el día del parto la cerda recibe no fue alimentada.

\section{- Atención del parto}

Una vez que las cerdas cumplieron los $114( \pm 2)$ días de gestación presentaron los siguientes síntomas:

- Inquietud y nerviosismo, se observaba que la cerda empezaba a echarse y pararse constantemente.

- Hinchazón y enrojecimiento de la vulva, con mucosidad sanguinolenta.

- Se observó inflamación de la ubre con escurrimiento de calostro.

- Finalmente la manifestación de contracciones y la expulsión del primer feto dio inicio al parto.

La duración del parto varía según la cerda y el tamaño de la camada, en la mayoría de todos los casos no se prolongaron por más de 2 horas, la finalización del parto se dio con la expulsión de la placenta. Después del parto algunas cerdas presentaron metritis siendo tratadas con trimetropin vía intramuscular.

\section{- Atención de los lechones}

La atención de los lechones el día del parto fue de vital importancia para asegurar su supervivencia, debido a que el periodo comprendido entre el nacimiento hasta las cuatro primeras semanas de vida se considera un periodo crítico para el lechón; las actividades que se realizaron fueron las siguientes:

- Limpieza de membranas fetales, empezando por el morro para permitir al lechón respirar y evitar que este muera por asfixia, una vez expulsado el lechón era secado, para evitar hipotermia; ya que nacen húmedos, estas actividades fueron realizadas con hojas de periódico y trapos.

- El corte, se lo realizó con la ayuda de una pinza hemostática y tijera quirúrgica a la altura de $2 \mathrm{~cm}$ desde la base del ombligo, la desinfección con una solución de yodo al 10\% evitó la infección del ombligo.

- Ayuda en la primera toma de calostro, esta actividad se la realizó debido a que algunos lechones nacieron muy débiles y resultaba difícil para ellos acceder hacia un pezón.

- Aplicación de 1 cc de Hierro (IM), con la finalidad de evitar anemia.

- Descolmillado se lo ejecutó si se observaba lesiones en la ubre de la madre ó heridas en el morro de los lechones.

- Registro de peso, sexo y número de cada lechón.

- Marcación, la investigación adopto el modelo de marcación nacional en decenas (Anexo 1); esto quiere decir que si una cerda alumbra hoy le corresponderá a esa camada la numeración del 1 al 10, si el número de lechones es superior a 10 se utilizó la marca X para identificar a esos lechones, la siguiente camada adoptará la numeración comprendida entre el numero 11 al 20, por ejemplo (Cuadro No 12): 


\section{Cuadro No 15}

Sistema de marcación para lechones utilizado en la investigación

\begin{tabular}{|l|l|l|l|}
\hline Lechón No & \multicolumn{1}{|c|}{ Sexo } & Lechón No & \multicolumn{1}{|c|}{ Sexo } \\
\hline 1 & Hembra & 11 & Hembra \\
3 & Hembra & 12 & Hembra \\
5 & Macho & 13 & Macho \\
6 & Macho & 14 & Macho \\
7 & Macho & 15 & Macho \\
8 & Hembra & 17 & Macho \\
9 & Hembra & 18 & Hembra \\
$10 x$ & Macho & 19 & Hembra \\
$1 x$ & Macho & $11 x$ & Macho \\
$2 x$ & Macho & $12 x$ & Macho \\
\hline
\end{tabular}

De 7 a 10 días después del parto se procedió a realizar las siguientes cirugías menores:

- Corte de colas, esta actividad se la realizó con la finalidad de prevenir problemas futuros de caudofagia (mordedura de la cola) después del destete, el corte se realizaba a $102 \mathrm{~cm}$ de la base de la cola.

- Castración, realizada a los lechones machos, con la finalidad de disminuir la libido y promover la ganancia de peso.

\section{- Preparación del alimento}

El alimento para cerdas consistía en rechazos frescos de plátano y palmito, mas suplemento proteico que fue preparado en la mezcladora de la Universidad Tecnológica Equinoccial, la materia prima utilizada consistía en maíz, soya, polvillo de arroz, palmiste, harina de pescado, melaza y pre mezcla, que una vez preparada con diferentes niveles de proteína y energía según el tratamiento era suministrado a las cerdas.

Para preparar el alimento de los lechones de la misma manera se utilizó maíz, soya, harina de pescado, pre mezcla y se adicionó azúcar reemplazando a la melaza, también se utilizó harinas de rechazos de plátano y palmito como materia prima.

La preparación de las harinas a partir de los rechazos se lo realizó desecando los rechazos en una estufa y luego moliéndolos, de esta manera se obtuvo las harinas para ser mezcladas con la demás materias primas.

\section{- Suministro de alimento a las cerdas}

La alimentación de las cerdas se realizó en comederos individuales, esto es, que las cerdas salían del corral de maternidad y se dirigían hacia los comederos individuales en grupos de 5 animales, una vez consumida la ración de alimento volvían al corral de maternidad.

Las cerdas fueron alimentadas dos veces al día, el primer suministro de alimento se lo realizó en horas de la mañana proporcionando $10 \mathrm{kgm}$ de rechazo de plátano ó palmito según el tratamiento (Cuadro No 9), posteriormente en la tarde se alimentaba con 685 gr de suplemento proteico (concentrado) al tratamiento plátano y 810 gr de suplemento proteico (concentrado) al tratamiento palmito, para el tratamiento testigo se le proporcionaba $6 \mathrm{~kg} /$ día de concentrado comercial de la siguiente manera, $3 \mathrm{~kg}$ en la mañana y $3 \mathrm{~kg}$ en la tarde.

\section{- Suministro de alimento a los lechones}

El manejo de la alimentación de la camada se lo hizo con el criterio de alimentación Ad libitum, esto indica: proporcionar a la camada el alimento que desee consumir a voluntad y al igual que las madres se les suministró alimento dos veces al día. La alimentación sólida empezó a la $4^{\text {ta }}$ semana de vida aplicando $1 \mathrm{kgm} /$ día para posteriormente aumentar la dosis según la edad de la camada, hasta llegar a los 4 últimos días antes del destete suministrando 4 kg/día y suprimiendo el consumo de leche materna. 
La alimentación de los lechones, se realizó de la siguiente manera:

\section{Cuadro No 16}

Manejo de la alimentación de lechones en la investigación

\begin{tabular}{|l|l|}
\hline \multicolumn{1}{|c|}{ Edad de la camada } & \multicolumn{1}{c|}{ Alimento } \\
\hline $1^{\text {ra }}$ semana & Leche materna \\
$2^{\text {da }}$ semana & Leche materna \\
$3^{\text {ra }}$ semana & Leche materna \\
$4^{\text {ta }}$ semana & Leche materna + Concentrado \\
$5^{\text {ta }}$ semana & Leche materna + Concentrado \\
$6^{\text {ta }}$ semana & Leche materna + Concentrado \\
4 días antes del destete & Concentrado \\
\hline
\end{tabular}

\section{- Manejo sanitario}

La limpieza de corrales se realizó diariamente, consistió en la eliminación de heces fecales del piso con la ayuda de un cepillo y agua, además se aprovechaba esta actividad para realizar un baño a las cerdas, posteriormente una vez por semana se realizaba una desinfección de los corrales de maternidad con una solución de yodo, estas actividades tenían la finalidad de mantener los corrales limpios y evitar la presencia y propagación de enfermedades.

En el caso de las cerdas el manejo de biológicos (vacunas), se lo realizó en la etapa de gestación quedando inmunizadas para la etapa de lactancia; cabe recalcar que durante los últimos meses de investigación se presentó un brote de parvo virosis por lo que se procedió aplicar la vacuna a las cerdas durante la lactancia.

El manejo sanitario en lechones consistió básicamente en mantener camas limpias (viruta), las mismas que se utilizaron hasta la $4^{\text {ta }}$ semana de vida, además se procuró vigilar constantemente la aparición de diarreas, con la finalidad de controlar y evitar que se agrave el problema, la aplicación de biológicos en lechones se lo hizo manejando el siguiente calendario:

\section{Cuadro No 17}

Calendario de vacunación para lechones utilizado en la investigación

\begin{tabular}{|l|l|}
\hline Edad del lechón & \multicolumn{1}{|c|}{ Vacuna } \\
\hline 9 días & $1^{\text {ra }}$ dosis Mico plasma \\
35 días & Bacterina mixta \\
45 días & $2^{\text {da }}$ dosis Mico plasma \\
\hline
\end{tabular}

La aparición de diarreas en lechones fue esporádica, principalmente se presentaba durante los primeros días que se ofrecía alimento sólido, la duración de la diarrea fue de 3 a 5 días, sin prolongarse por más tiempo debido al tratamiento que se realizaba a los lechones afectados, el tratamiento consistía en la aplicación de enrofloxacina mas un hepatoprotector, vía intramuscular.

\section{- Manejo de registros}

La información obtenida fue registrada diariamente en hojas donde constaba la información de la cerda y su camada, los registros levantados fueron de alimentación y pesos.

Para el control de la alimentación se procedía a registrar el consumo y desperdicio del alimento ofrecido a la cerda y a su camada, para lo cual se pesaba el alimento ofrecido y el alimento sobrante (desperdicio). El registro de peso de la cerda y la camada se lo realizó al $1^{\text {er }}$ día posparto, 21 y 45 días respectivamente.

Además en los formatos constaba la información individual de cada animal como:

- Fecha de parto,

- $\quad N^{\circ}$ de cerda y camada,

- $\quad N^{\circ}$ de nacidos vivos y muertos,

- Fecha de aplicación de biológicos (lechones), etc. 


\section{- Materiales e Insumos}

\section{- Materiales}

Los materiales utilizados en la investigación para realizar actividades físicas, tales como: limpieza de corrales, pesaje de animales, preparación de alimento, etc., fueron los siguientes:

\section{- Insumos}

Los insumos utilizados consistían principalmente en materia prima para la elaboración de alimento, así como también medicamentos:

\begin{tabular}{|l|l|}
\hline MATERIALES & INSUMOS \\
\hline
\end{tabular}

\begin{tabular}{|l|l|}
\hline Escoba & Maíz molido \\
\hline Pala & Soya \\
\hline Carretilla & Polvillo de cono \\
\hline Baldes & Melaza \\
\hline Bomba de fumigar & Harina de pescado \\
\hline Bascula (pesaje de cerdas) & Palmiste \\
\hline Balanza (pesaje de lechones) & Harina de plátano \\
\hline Moledora & Harina de palmito \\
\hline Mezcladora & Azúcar \\
\hline Balanza analítica & Sal yodada \\
\hline Jeringas & Núcleo vitamínico \\
\hline Bisturí & Rechazos de plátano \\
\hline Pinza hemostática & Rechazos de palmito \\
\hline Pinza descolmilladora & Vacuna "micoplasma" \\
\hline & Vacuna "cólera porcina" \\
\hline & Vacuna "Bacterina mixta" \\
\hline & Yodo \\
\hline & Enrofloxacina \\
\hline & Hepato protector \\
\hline & Matagusanos \\
\hline & Complejo B \\
\hline & \\
\hline
\end{tabular}

\section{Etapa de Engorde}

\section{- Factores en Estudio}

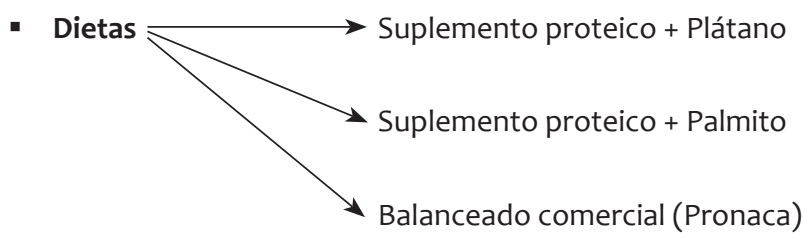

- Mortalidad

- Costos de producción

- Características de Unidades Experimentales

- Número de unidades experimentales:

30 lechones

- Raza:

Landrace- Poland (mestizos)

- Edad:

45 días

- Características del ensayo

- Número de tratamientos:

03

- Número de unidades experimentales / tratamiento: 10

- Área útil del experimento:

$51,15 \mathrm{~m}^{2}$

- Dimensiones de la porqueriza:

5,50 m (largo) x 3,10 m (ancho)

- $\quad$ Área total de cada porqueriza:

$17,05 \mathrm{~m}^{2}$

- Variables Independientes

- Suplemento proteico + plátano

- Suplemento proteico + palmito 
- Variables dependientes

- Incremento diario de peso

- Conversión alimenticia

- Mortalidad

- Relación beneficio- costo de los tratamientos

\section{- Tratamientos evaluados}

Los tratamientos evaluados fueron un suplemento proteico más dos materiales disponibles en la zona como son el plátano barraganete y el palmito, además se utilizó un testigo absoluto para las comparaciones correspondientes en el siguiente cuadro:

\section{Cuadro No 18}

\section{Simbología y tratamientos evaluados}

\begin{tabular}{|l|l|}
\hline SIMBOLOGíA & \multicolumn{1}{|c|}{ TRATAMIENTOS } \\
\hline T1 & $\begin{array}{l}80 \% \text { de Suplemento proteico (crecimiento y acabado) }+20 \% * \text { de plátano } \\
\text { barraganete }\end{array}$ \\
\hline T2 & Testigo "Balanceado comercial" (crecimiento y acabado) \\
\hline T3 & $90 \%$ de Suplemento proteico (crecimiento y acabado) $+10 \% *$ de palmito \\
\hline
\end{tabular}

*Calculado en base seca.

La composición y análisis calculados de las dietas experimentales para el estudio, consistió de dos raciones con productos convencionales en cerdos en crecimiento y acabado se detallan en los siguientes cuadros:

\section{Cuadro No 19}

Composición de las dietas (Kg) experimentales para cerdos en la fase

\begin{tabular}{|c|c|c|}
\hline Ingredientes & $\begin{array}{c}\text { Suplemento. Dieta } \\
\text { plátano }(\mathrm{Kg})\end{array}$ & $\begin{array}{c}\text { Suplemento. Dieta } \\
\text { palmito (Kg) }\end{array}$ \\
\hline Maíz & 10 & 22 \\
\hline Soya & 37 & 25 \\
\hline Polvillo & 20 & 20 \\
\hline Pescado & 15 & 15 \\
\hline Palmiste & 10 & 10 \\
\hline Melaza & 10 & 10 \\
\hline Pre mezcla & 2.5 & 2.5 \\
\hline
\end{tabular}

\section{Cuadro No 20}

Composición de las dietas (Kg) experimentales para cerdos en la fase de Acabado

\begin{tabular}{|l|l|l|}
\hline \multicolumn{1}{|c|}{ Ingredientes } & \multicolumn{1}{|c|}{$\begin{array}{c}\text { Suplemento. Dieta } \\
\text { plátano }(\mathrm{kg})\end{array}$} & \multicolumn{1}{c|}{$\begin{array}{c}\text { Suplemento. Dieta } \\
\text { palmito } \mathbf{~ K g )}\end{array}$} \\
\hline Maíz & 10 & 38.58 \\
\hline Soya & 37 & 13.91 \\
\hline Polvillo & 20 & 20 \\
\hline Pescado & 15 & 5 \\
\hline Palmiste & 10 & 10 \\
\hline Melaza & 10 & 10 \\
\hline Pre mezcla & 2.5 & 2.5 \\
\hline
\end{tabular}

\section{Cuadro No 21}

Composición de pre mezcla utilizada en las dietas experimentales para cerdos en la fase de crecimiento y acabado

\begin{tabular}{|l|l|}
\hline \multicolumn{2}{|c|}{ Ingredientes } \\
\hline Producto & $100 \mathrm{~g}$ \\
\hline Sal & $500 \mathrm{~g}$ \\
\hline Maíz & $1900 \mathrm{~g}$ \\
\hline
\end{tabular}


El suministro de las diferentes raciones alimenticias se realizó de acuerdo al peso de los animales en las diferentes fases del cerdo, que se muestran en el siguiente cuadro.

\section{Cuadro No 22}

Suministro de alimento en base seca (g.) de acuerdo al peso promedio de los cerdos en la fase de crecimiento y acabado

\begin{tabular}{|l|l|}
\hline Peso/ animal & Volumen/ ración \\
\hline $10 \mathrm{Kg}$ & $600 \mathrm{~g} \mathrm{M} / \mathrm{S}$ \\
\hline $15 \mathrm{Kg}$ & $900 \mathrm{~g} \mathrm{M} / \mathrm{S}$ \\
\hline $20 \mathrm{Kg}$ & $1250 \mathrm{~g} \mathrm{M} / \mathrm{S}$ \\
\hline $25 \mathrm{Kg}$ & $1475 \mathrm{~g} \mathrm{M} / \mathrm{S}$ \\
\hline $35 \mathrm{Kg}$ & $1700 \mathrm{~g} \mathrm{M} / \mathrm{S}$ \\
\hline $48 \mathrm{Kg}$ & $2100 \mathrm{~g} \mathrm{M} / \mathrm{S}$ \\
\hline $60 \mathrm{Kg}$ & $2500 \mathrm{~g} \mathrm{M} / \mathrm{S}$ \\
\hline $80 \mathrm{Kg}$ & $3000 \mathrm{~g} \mathrm{M} / \mathrm{S}$ \\
\hline $100 \mathrm{Kg}$ & $3500 \mathrm{~g} \mathrm{M} / \mathrm{S}$ \\
\hline
\end{tabular}

Elaborado por: Valle, O y Barúa, J (1969)

\section{Cuadro No 23}

Cálculo del alimento proporcionado a los cerdos en base seca, en las dietas de plátano + suplemento proteico y palmito +suplemento proteico

\begin{tabular}{|l|l|l|l|l|l|}
\hline & & \multicolumn{2}{|c|}{ Dieta de plátano } & \multicolumn{2}{c|}{ Dieta de palmito } \\
\hline $\begin{array}{c}\text { Peso/ } \\
\text { animal }\end{array}$ & Volumen/ ración & Plátano & $\begin{array}{c}\text { Suplemento. } \\
\text { Proteico }\end{array}$ & Palmito & $\begin{array}{c}\text { Suplemento. } \\
\text { Proteico }\end{array}$ \\
\hline $10 \mathrm{Kg}$ & $600 \mathrm{~g} \mathrm{M} / \mathrm{S}$ & $459 \mathrm{~g}$ & $480 \mathrm{~g}$ & $571 \mathrm{~g}$ & $540 \mathrm{~g}$ \\
\hline $15 \mathrm{Kg}$ & $900 \mathrm{~g} \mathrm{M} / \mathrm{S}$ & $689 \mathrm{~g}$ & $720 \mathrm{~g}$ & $857 \mathrm{~g}$ & $810 \mathrm{~g}$ \\
\hline $20 \mathrm{Kg}$ & $1250 \mathrm{~g} \mathrm{M} / \mathrm{S}$ & $953 \mathrm{~g}$ & $1000 \mathrm{~g}$ & $1190,5 \mathrm{~g}$ & $1125 \mathrm{~g}$ \\
\hline $25 \mathrm{Kg}$ & $1475 \mathrm{~g} \mathrm{M} / \mathrm{S}$ & $1129,8 \mathrm{~g}$ & $1180 \mathrm{~g}$ & $1404,76 \mathrm{~g}$ & $1327,5 \mathrm{~g}$ \\
\hline $35 \mathrm{Kg}$ & $1700 \mathrm{~g} \mathrm{M} / \mathrm{S}$ & $1302,2 \mathrm{~g}$ & $1360 \mathrm{~g}$ & $1619,05 \mathrm{~g}$ & $1530 \mathrm{~g}$ \\
\hline $48 \mathrm{Kg}$ & $2100 \mathrm{~g} \mathrm{M} / \mathrm{S}$ & $1608,58 \mathrm{~g}$ & $1680 \mathrm{~g}$ & $2000 \mathrm{~g}$ & $1890 \mathrm{~g}$ \\
\hline $60 \mathrm{Kg}$ & $2500 \mathrm{~g} \mathrm{M} / \mathrm{S}$ & $1914,98 \mathrm{~g}$ & $2000 \mathrm{~g}$ & $2380,9 \mathrm{~g}$ & $2250 \mathrm{~g}$ \\
\hline $80 \mathrm{Kg}$ & $3000 \mathrm{~g} \mathrm{M} / \mathrm{S}$ & $2297,9 \mathrm{~g}$ & $2400 \mathrm{~g}$ & $2857,1 \mathrm{~g}$ & $2700 \mathrm{~g}$ \\
\hline
\end{tabular}

*Dieta calculada para cada animal

\section{Diseño experimental}

- Tipo de diseño

Se empleó el diseño experimental completo al azar con diferente número de observaciones por tratamiento (DCA), constó de tres tratamientos, con un total de 30 unidades experimentales LandracePoland (mestizos).

\section{Cuadro No 24}

Esquema de ADEVA

\begin{tabular}{|l|c|}
\hline \multicolumn{1}{|c|}{ F.V } & GL \\
\hline TRATAMIENTOS & 2 \\
\hline T1 vs. T2, T3 & 1 \\
\hline T2 vs. T3 & 1 \\
\hline ERROR & 25 \\
\hline TOTAL & 27 \\
\hline
\end{tabular}

- Prueba de significancia

De acuerdo a los resultados obtenidos, se aplicó la prueba de Tukey al 5\%, para establecer la significancia estadística de las medias de los tratamientos evaluados, se determinó además mediante un nivel de confianza equivalente a 0,05 y 0,01; es decir 95\% y $99 \%$ de seguridad, respectivamente; y se aplica correlación ortogonal para las dietas en estudio.

\section{Datos y métodos empleados}

\section{- Incremento de peso}

Los pesos de las unidades experimentales fueron tomados de la siguiente manera:

\section{- Peso inicial de los cerdos:}

Se pesó cada lechón desde el inicio de la investigación, es decir 
al destete a los 45 días de edad, esta actividad se realizó con la ayuda de una balanza colgante de $100 \mathrm{~kg}$ y una estructura metálica tipo cajón creada para ese fin, los datos se los obtenía en las primeras horas de la mañana.

\section{- Pesos quincenales en el crecimiento y engorde de los cerdos:}

Se procedió a pesar cada cerdo desde el punto de partida de la investigación, es decir a los 45 días de edad, y cada quince días respectivamente hasta alcanzar el peso promedio de $80 \mathrm{~kg}$ por cada tratamiento, con el fin de obtener la ganancia de peso de los animales.

\section{- Pesos finales de los cerdos:}

Se pesó a los cerdos al cumplir con el peso promedio requerido (80 kg), esto en una balanza estática (romana).

Para obtener el incremento de peso se utilizó la siguiente fórmula:

\section{$\Delta$ de Peso $=$ Peso final - Peso inicial}

\section{- Conversión alimenticia}

Los datos se obtuvieron pesando el alimento proporcionado todos los días (suplemento proteico + plátano o palmito respectivamente) el cual se dividió para el incremento de peso.

El alimento se les proporcionó dos veces al día, el plátano (MS $20 \%$ de la dieta); el palmito (MS 10\% de la dieta) en las horas de la mañana, y el suplemento proteico tanto del plátano como del palmito en las horas de la tarde, el alimento sobrante que quedaba en la tarde o en la noche se lo pesaba el día siguiente.

Fórmula utilizada para la conversión alimenticia:

$$
\text { CA. }=\frac{\text { Alimento total consumido }}{\text { Incremento total de peso }}
$$

\section{- Mortalidad}

Se tomó el valor total de los tres tratamientos desde el inicio al final de la investigación los valores de mortalidad correspondientes a cada tratamiento.

Para obtener el valor de la mortalidad se empleó la siguiente fórmula:

$\% \mathrm{M}=$ Número total de animales muertos $\times 100$

\section{Población total}

\section{Análisis económico}

\section{- Costos de producción}

En el análisis económico se tomaron en cuenta los siguientes parámetros que serán citados posteriormente para cada tratamiento:

- Mano de obra

- Infraestructura

- Equipo con motor

- Equipo sin motor

- Depreciación

- Sanidad Animal

- Alimentación

- Transporte

- Electricidad

- Interés de capital invertido 


\section{Manejo del experimento}

\section{- Limpieza y desinfección de instalaciones}

Se realizó ocho días antes de iniciar con la investigación, procediendo a lavar y desinfectar las tres naves para cada tratamiento, también se hizo el chequeo de los materiales a utilizar como bebederos, comederos, balanzas.

El producto que se aplicó para la desinfección fue el Creso (1cc) litro agua), se realizó con la ayuda de una bomba de mochila y su aplicación fue dirigida hacia paredes, pisos y pasillos tanto del exterior como interior del plantel, y así tener un ambiente con menor presencia de agentes patógenos.

La limpieza de las naves fue realizada a diario, con la ayuda de escobas, suaves y sólidas, además cada 15 días se realizaba la limpieza general de pisos y paredes con detergentes.

\section{- Recepción y distribución de los cerdos}

Al cumplir 45 días de edad las camadas existentes en la granja, se los iba adquiriendo en número de diez para los diferentes tratamientos, se realizó el respectivo sorteo de los tratamientos quedando distribuidos de la siguiente manera:

- Primer tratamiento: Suplemento proteico + Plátano

- Segundo tratamiento: Balanceado Comercial

- Tercer tratamiento: Suplemento proteico + Palmito.

\section{- Identificación}

El sistema de identificación utilizado fue el sistema nacional de muesqueo de orejas, esta actividad se realizó diez días antes de empezar con la investigación de manera que no sufran un mayor estrés el animal.
Se empezó designando desde el número uno hasta el sesenta y siete en los diferentes tratamientos, que serán mejor detallados en el Anexo 6.

\section{- Calendario sanitario}

\section{Cuadro No 25}

\section{Calendario por edad, producto y dosis}

\begin{tabular}{|l|l|l|}
\hline \multicolumn{1}{|c|}{ Edad } & \multicolumn{1}{|c|}{ Producto } & \multicolumn{1}{c|}{ Dosis } \\
\hline 45 días & Cepa china & $2 \mathrm{ml} /$ animal \\
\hline 56 días & Enrofloxacina & $1 \mathrm{ml} /$ animal \\
\hline 71 días & Fenbendazol & $1 \mathrm{ml} /$ animal \\
\hline 102 días & Multi-reconstituyente & $3 \mathrm{~cm} /$ animal \\
\hline 117 días & Vacuna Pasteurella tipo I, II, III & $3 \mathrm{~cm} /$ animal \\
\hline 132 días & Fenbendazol & $4 \mathrm{ml} /$ animal \\
\hline
\end{tabular}

\section{- Cantidad de alimento suministrado}

El alimento fue calculado de acuerdo al requerimiento de proteína y energía requerida por los animales en las diferentes fases en la que el animal atravesó.

Es así que de acuerdo a la cantidad de proteína que tenía el plátano y el palmito se elaboraba el suplemento proteico hasta alcanzar el $16 \%$ de proteína requerido para la fase de crecimiento y así mismo para el caso de la fase de acabado 14\% de proteína.

La cantidad de alimento proporcionado a los animales, se basó en el peso de los mismos, en base seca, este punto se explica de mejor manera en el cuadro 10. 
- Materiales e Insumos

\begin{tabular}{|l|l|}
\hline MATERIALES & INSUMOS \\
\hline
\end{tabular}

\begin{tabular}{|l|l|}
\hline Kit de limpieza (escobas, pala, cepillos) & Maíz \\
\hline Balanza gramera & Soya \\
\hline Balanza colgante de $100 \mathrm{~kg}$ & Polvillo \\
\hline Balanza estática (romana) & Harina de pescado \\
\hline Mezcladora automática & Palmiste \\
\hline Sacos & Melaza \\
\hline Baldes & Sal \\
\hline Bomba para fumigar & Núcleo “Vitaminas + aminoácidos" \\
\hline Jeringas & Creolina \\
\hline Muesqueador & Cepa china \\
\hline Tabla de registros & Enrofloxacina \\
\hline & Multi-reconstituyente \\
\hline & Hepato- protector \\
\hline & Fenbendazol \\
\hline & Vacuna contra Pasteurella multocida tipo I, II, IIII \\
\hline & Formol \\
\hline & Matagusanos \\
\hline
\end{tabular}

\section{Resultados y discusión}

\section{Etapa de Gestación}

\section{- Incremento de Peso}

En el cuadro No 10, se observa que para el incremento de peso en cerdas gestantes de 1 a 110 días, se encontraron diferencias estadísticas significativas entre tratamientos, así como entre T1 (Plátano mas suplemento proteico) versus T2 (Palmito mas suplemento proteico), T3 (Balanceado Comercial); por lo que, se acepta la hipótesis alternativa, que señala que la utilización de plátano y palmito reemplazan eficientemente a la disminución parcial del elemento energético maíz en cerdos en la etapa de gestación.

Mientras que para T2 (Palmito) vs T3 (Balanceado comercial) no se encontraron diferencias estadísticas significativas. Además, se obtuvo un coeficiente de varianza de $11,44 \%$ lo que se encuentra dentro del rango establecido para este tipo de investigación.

\section{Cuadro No 26}

Análisis estadístico de varianza para el incremento de peso en cerdas gestantes de 1 a 110 días.

\begin{tabular}{|c|c|c|c|c|c|c|}
\hline F.V. & GL & SC & $\mathrm{CM}$ & $\mathbf{F}$ & VALOR P & \\
\hline TRATAMIENTOS & 2 & 0,04 & 0,02 & 5,21 & 0,0488 & $*$ \\
\hline T1 Vs T2,T3 & $\mathbf{1}$ & 0,03 & 0,03 & 9,05 & 0,0237 & $*$ \\
\hline T2 rs T3 & $\mathbf{1}$ & 0,00 & 0,00 & 0,57 & 0,4794 & ns \\
\hline ERROR & 6 & 0,02 & 0,00 & & & \\
\hline TOTAL & 8 & 0,06 & & & & \\
\hline C.V $\%$ & 11,14 & & & & & \\
\hline
\end{tabular}

Fuente: Investigación de campo.

En el cuadro No 11, se presentan los promedios de incrementos de peso diario, obtenidos mediante la prueba de Tukey al $5 \%$ de probabilidad, donde no se presento rangos de significancia estadística. Mientras que en diferencias numéricas el T1 (Suplemento proteico + Palmito) supera al resto de tratamientos, obteniendo $67,50 \mathrm{~kg}$ de incremento de peso de o - 110 días y 0,62 kg/día.

\section{Cuadro No 27}

Promedios de incrementos de pesos en cerdas al final de la etapa de gestación empleando diferentes dietas alimentarias. UTE. Santo Domingo. 2008.

\begin{tabular}{|c|c|c|c|}
\hline Tratamientos & Incremento total (Kg) & Incremento (Kg/dia) & Rango \\
\hline 2 (Sup proteico + palmitn) & 67,50 & 0,62 & 2 \\
\hline 3 (B almonedo comercinl) & 63,00 & 0,58 & $\mathbf{2}$ \\
\hline 1 (Stop protrion + plinino) & 52,25 & 0,47 & $\mathbf{2}$ \\
\hline
\end{tabular}

Fuente: Investigación de campo. 
Gráfico $\mathrm{N}_{1}$

Promedios de incrementos de pesos en cerdas al final de la etapa de gestación empleando diferentes dietas alimentarias. UTE. Santo Domingo. 2008. Fuente: Investigación de campo.

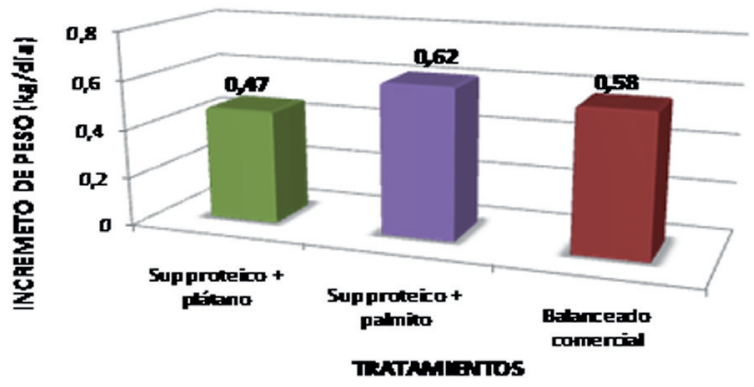

- Peso post parto

Para la variable peso post parto en cerdas gestantes no se encontraron diferencias estadísticas significativas entre tratamientos, por lo que se acepta la hipótesis nula, la cual señalaba que la utilización de plátano o palmito no reemplazan eficientemente a la disminución parcial del elemento energético maíz en cerdos en la etapa de gestación; mas, numéricamente existió diferencia, donde el T1 (Suplemento proteico + Plátano) y el T2 (Suplemento proteico + Palmito) superaron con 15 y $13,88 \mathrm{~kg}$ respectivamente, al T3 (Balanceado comercial) el cual mostró un peso promedio post parto de $157 \mathrm{kgm}$.

El coeficiente de varianza para esta variable fue de 9,89\%, lo cual garantiza la veracidad de la información presentada en esta investigación, encontrándose dentro de los parámetros establecidos para este tipo de ensayos.
Cuadro No 28

Análisis estadístico de varianza para la variable peso post parto en la evaluación del uso del plátano o palmito frescos más suplemento proteico en alimentación de cerdas gestantes. UTE. Santo Domingo. 2008.

\begin{tabular}{lcccccc}
\hline \multicolumn{1}{c}{ F.V. } & GL & SC & CM & F & VALOR P & \\
\hline \hline TRATAMIENTOS & 2 & 322,81 & 161,41 & $\mathbf{0 , 5 8}$ & 0,5869 & $\mathrm{~ns}$ \\
T1 Ys. T2,T3 & 1 & 88,67 & 88,67 & 0,32 & 0,7919 & $\mathrm{~ns}$ \\
T2 rs. T3 & 1 & 270,90 & 270,90 & 0,98 & 0,3615 & $\mathrm{~ns}$ \\
ERROR & 6 & 1669,69 & 276,78 & & & \\
TOTAL & 8 & 1983,50 & & & & \\
\hline C.V 46 & 9,89 & & & & & \\
\hline
\end{tabular}

Fuente: Investigación de campo.

Cuadro No 29

Promedios al primer día post parto en la evaluación del uso del plátano o palmito frescos más suplemento proteico en alimentación de cerdas gestantes. UTE. Santo Domingo. 2008.

\begin{tabular}{ccc}
\hline Tra tamientos & Peso post parto (kg) & Rango \\
\hline \hline 1 (Sup protrico + plano) & 170,88 & $\mathbf{a}$ \\
2 (Sup proteico + palmito) & 172,00 & $\mathbf{a}$ \\
3 (B.tanceaio comercial) & 157,00 & $\mathbf{a}$ \\
\hline
\end{tabular}

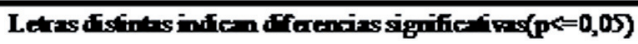

Fuente: Investigación de campo.

Gráfico $\mathbf{N}^{\circ} 2$.

Promedios al primer día post parto en la evaluación del uso del plátano o palmito frescos más suplemento proteico en alimentación de cerdas gestantes. UTE. Santo Domingo. 2008.

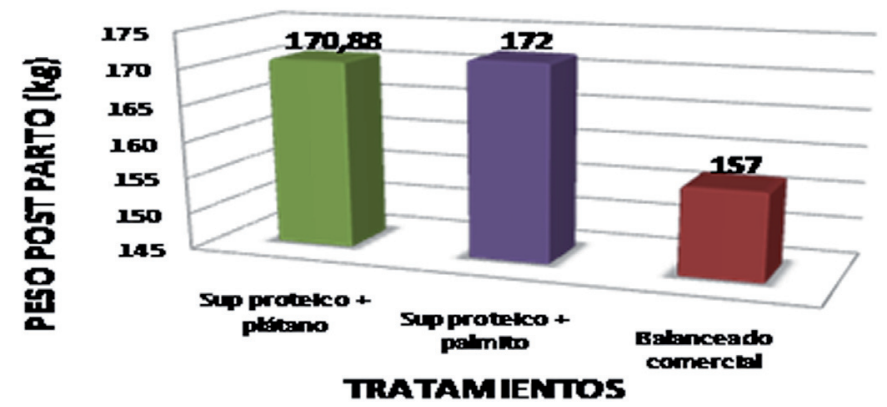


- Peso de Lechones

Para esta variable no se encontró diferencia estadística significativa entre tratamientos; mientras que, en comparaciones ortogonales entre T1 (Suplemento proteico + Plátano) versus T2 (Suplemento proteico + Palmito), T3 (Balanceado comercial), se observaron diferencias estadísticas significativas. En análisis entre T2 (Suplemento proteico + Palmito) versus T3 (Balanceado comercial), (cuadro No 14)

El coeficiente de variación para esta variable evaluada fue del $13.23 \%$, con lo cual se garantiza que la investigación ha sido bien concluida de conformidad con los datos reportados.

Los promedios de pesos analizados mediante prueba de significación de Tukey al 5 \%, se puede observar en el cuadro No 15, en el cual no se detectaron rangos estadísticos diferentes entre repeticiones. Numéricamente la T3 (Balanceado comercial), tuvo un mayor peso promedio con un valor de 1547, 45g; mientras T1 (Suplemento proteico + Plátano) fue el presentó un menor peso promedio de 1243,80 g.

Cuadro No 30

Análisis estadístico de varianza para la variable peso de lechones, en la evaluación del uso del plátano o palmito frescos más suplemento proteico en alimentación de cerdas gestantes. UTE. Santo Domingo. 2008.

\begin{tabular}{lcccccc}
\hline \multicolumn{1}{c}{ F.V. } & GL & SC & CM & F & VALOR P & \\
\hline \hline TRATAMIIENTOS & 2 & 139107,78 & 69553,89 & 4,11 & 0,0753 & ns \\
T1 vS T2,T3 & 1 & 133533,03 & 133533,03 & 7,88 & 0,0309 & $*$ \\
T2 vs T3 & 1 & 15192,00 & 15192,00 & 0,90 & 0,3802 & ns \\
ERROR & 6 & 101646,35 & 16941,06 & & & \\
TOTAL & 8 & 240754,13 & & & & \\
\hline C.V $\%$ & 9,47 & & & & & \\
\hline
\end{tabular}

ruente: Investigacion de campo.

\section{Cuadro No 31}

Promedios para la variable peso promedio de lechones, en la evaluación del uso del plátano o palmito frescos más suplemento proteico en alimentación de cerdas gestantes. UTE. Santo Domingo. 2008.

\begin{tabular}{|c|c|c|}
\hline Tratamientos & Peso promedio lechón (g) & Rango \\
\hline 3 (Balancraio comercial) & 1547,45 & $\mathbf{a}$ \\
\hline 2 (Sup protrion + palmito) & 1434,93 & $\mathbf{a}$ \\
\hline 1 (Sup protrico + p1/tano) & 1243,80 & $\mathbf{a}$ \\
\hline
\end{tabular}

Fuente: Investigación de campo.

\section{Gráfico No 3}

Promedios para la variable peso promedio de lechones, en la evaluación del uso del plátano o palmito frescos más suplemento proteico en alimentación de cerdas gestantes. UTE. Santo Domingo. 2008.

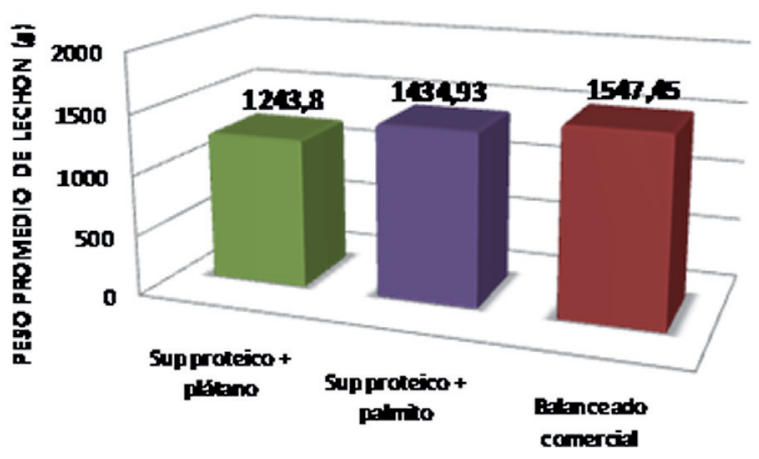

- Conversión alimenticia

La conversión alimenticia en cerdas gestantes tanto para los tratamientos como para las comparaciones ortogonales T1 (Suplemento proteico + Plátano) versus T2 (Suplemento proteico + Palmito), T3 (Balanceado comercial), se encontró significancia, razón por la cual se acepta la hipótesis alternativa y se rechaza la hipótesis nula. Sin embargo para la comparación ortogonal T2 (Suplemento proteico + Palmito) versus (Balanceado comercial) los resultados observados no demuestran significancia entre dichos tratamientos, aceptándose la hipótesis nula. (Cuadro No 16) 
El coeficiente de variación para este periodo de evaluación fue de $13,77 \%$, con lo que se garantiza que la investigación ha sido bien concluida de conformidad con los datos reportados. En el Cuadro No 17, el cual detalla los promedios para la variable conversión alimenticia, los tres tratamientos evaluados en la investigación, son estadísticamente iguales, pero numéricamente la mejor conversión se dio en el tratamiento T2 (Suplemento proteico + Palmito) con un valor de 2,99.

\section{Cuadro No 32}

Análisis estadístico de varianza para la variable conversión alimenticia, en la evaluación del uso del plátano o palmito frescos más suplemento proteico en alimentación de cerdas gestantes. UTE. Santo Domingo. 2008.

\begin{tabular}{lcccccc}
\hline \multicolumn{1}{c}{ F.V. } & GL & SC & CM & F & VALORP & \\
\hline \hline TRATAMIENTOS & 2,00 & $\mathbf{2 , 0 0}$ & $\mathbf{1 , 0 0}$ & $\mathbf{4 , 4 8}$ & $\mathbf{0 , 0 5}$ & $*$ \\
T1 vs. T2,T3 & 1,00 & $\mathbf{1 , 9 3}$ & $\mathbf{1 , 9 3}$ & $\mathbf{8 , 6 5}$ & $\mathbf{0 , 0 3}$ & $*$ \\
T2 vs. T3 & 1,00 & $\mathbf{0 , 0 0}$ & $\mathbf{0 , 0 0}$ & $\mathbf{0 , 0 2}$ & $\mathbf{0 , 8 9}$ & ns \\
ERROR & 6,00 & $\mathbf{1 , 2 1}$ & $\mathbf{0 , 2 0}$ & & & \\
TOTAL & 8,00 & $\mathbf{3 , 3 4}$ & & & & \\
\hline C.V \% & $\mathbf{1 3 , 7 7}$ & & & & & \\
\hline
\end{tabular}

Fuente: Investigación de campo

\section{Cuadro No 33}

Promedios para la conversión alimenticia, en la evaluación del uso del plátano o palmito frescos más suplemento proteico en alimentación de cerdas gestantes. UTE. Santo Domingo. 2008.

\begin{tabular}{ccc}
\hline Tratamientos & Conversión alimenticia & Rango \\
\hline \hline 2 (Sup protei co + palmito) & $\mathbf{2 , 9 9}$ & $\mathrm{a}$ \\
3 (Balanceado comercial) & $\mathbf{3 , 0 5}$ & $\mathrm{a}$ \\
1(Sup proteico + plátano) & $\mathbf{3 , 9 6}$ & $\mathrm{a}$ \\
\hline
\end{tabular}

Letras distintas indican diferencias sigrificativas $(p<=0,05)$

Fuente: Investigación de campo.

\section{Gráfico No 4}

Conversión alimenticia, en la evaluación del uso del plátano o palmito frescos más suplemento proteico en alimentación de cerdas gestantes. UTE. Santo Domingo. 2008.

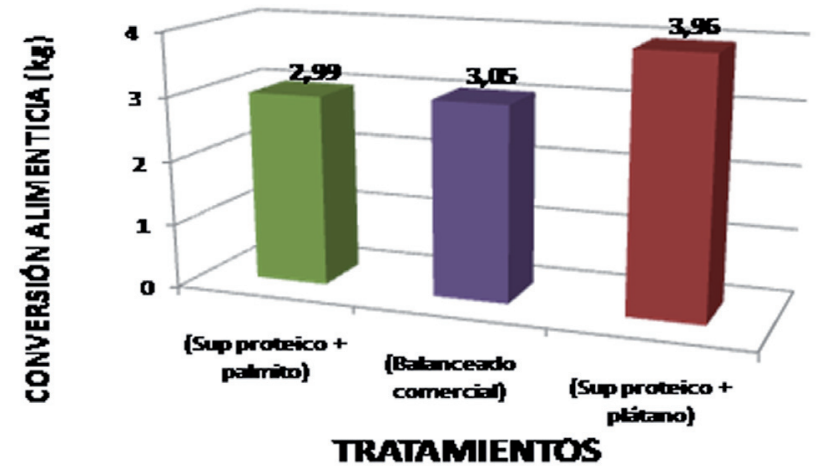

Fuente: Investigación de campo

\section{- Costos de Producción}

En el cuadro No 18, se pueden apreciar los costos de producción de cada tratamiento. En el cual se estima que el más alto costo de producción lo presentan el T2 (Balanceado comercial) con un valor de $\$ 262,76$ USD y el menor costo se aprecia para el tratamiento T1 (Suplemento proteico + Plátano) con un valor de \$182,34 USD

\section{Cuadro No 34}

Costos de producción por cerda

\begin{tabular}{|c|c|c|c|}
\hline CONCE PT O & $\begin{array}{c}\text { T1 } \\
\text { PLATANO FRESCO } \\
\text { SUPLE AEE NTO PROTE ICO }\end{array}$ & $\begin{array}{c}\text { T2 } \\
\text { PALMIT O FRE SCO } \\
\text { SUPLEMENTO PROTEICO }\end{array}$ & $\begin{array}{c}\text { T3 } \\
\text { BALANCE ADO } \\
\text { CONERCIAL }\end{array}$ \\
\hline CABT OSHXXS & 203,78 & 223,7 & 2023,73 \\
\hline CEST OSVATIARES & 494,09 & 429,02 & 293,47 \\
\hline 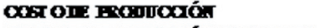 & 729,36 & 663,25 & 525,52 \\
\hline 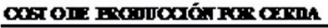 & 18,34 & 221,0 & 262,76 \\
\hline
\end{tabular}
Thepen and (490)

\section{Etapa de Lactancia}

- Incremento de peso

Del $1^{\text {er }}-21^{\text {avo }}$ día de vida en lechones

En el Cuadro No 19, se puede apreciar el análisis estadístico de varianza en el cual se pudo observar que no existieron diferencias sig- 
nificativas entre tratamientos y repeticiones.

Además en este mismo cuadro se aprecian las comparaciones ortogonales realizadas, siendo las comparaciones entre el T1 vs. T2, T3 y el T2 vs. T3; en las cuales se pudo observar que no se presentaron diferencias estadísticas.

El coeficiente de variación para este periodo de evaluación fue de $16.07 \%$, lo que determina que la investigación ha sido bien concluida.

\section{Cuadro No 35}

Análisis de varianza del incremento de peso diario en lechones desde el $1^{\circ}$ a $21^{\circ}$ días de evaluación.

\begin{tabular}{|l|l|l|l|l|l|}
\hline \multicolumn{1}{|c|}{ F.V. } & GL & SC & CM & \multicolumn{1}{c|}{ F } & Valor $\mathbf{P}$ \\
\hline TRATAMIENTOS & 2 & 0 & 0 & 0,44 & $0,6611 \mathrm{~ns}$ \\
T1 vs. T2,T3 & 1 & 0 & 0 & 0,47 & $0,5139 \mathrm{~ns}$ \\
T2 vs. T3 & 1 & 0 & 0 & 0,41 & $0,5420 \mathrm{~ns}$ \\
REPETICIONES & 4 & 0 & 0 & 0,14 & $0,9644 \mathrm{~ns}$ \\
ERROR & 8 & 0,04 & 0 & & \\
TOTAL & 14 & 0,05 & & & \\
\hline C.V. \% & 16,07 \\
\hline
\end{tabular}

** altamente significativo; * significativo; ns no significativo.

Mediante prueba de significación de rangos múltiples de Tukey al $5 \%$, no se detectaron rangos estadísticos diferentes entre tratamientos. Numéricamente el T1 (B. comercial) tuvo un mayor incremento de peso con un promedio de $0.21 \mathrm{~kg} /$ día y finalmente el tratamiento 2 (B. H. plátano) presentó la menor ganancia diaria con un valor de $0.17 \mathrm{~kg} /$ día. (Cuadro No 20, página 30).

\section{Cuadro No 36}

Promedio del incremento de peso diario (kg) por tratamientos desde $1^{\text {er }}$ día hasta los 21 días de lactancia en lechones. Santo Domingo, 2007.

\begin{tabular}{|l|c|c|c|}
\hline \multicolumn{1}{|c|}{ Tratamientos } & $\begin{array}{c}\text { Incremento de peso } \\
\text { total }(\mathrm{kg})\end{array}$ & $\begin{array}{c}\text { Incremento de peso } \\
\text { diario }(\mathrm{kg})\end{array}$ & Rangos \\
\hline 1 (B. comercial) & 4,13 & 0,21 & $\mathrm{a}$ \\
3 (B. H. palmito) & 3,46 & 0,19 & a \\
2 (B. H. plátano) & 3,83 & 0,17 & a \\
\hline \multicolumn{2}{|r|}{ Letras distintas indican diferencias significativas $(p<=0,05)$} \\
\hline
\end{tabular}

Se puede observar los promedios de incrementos de pesos analizados mediante prueba de significación de Tukey al 5 \%, en el cual no se detectaron rangos estadísticos diferentes entre repeticiones. Numéricamente la R2 tuvo un mayor incremento de peso con un promedio de $0.21 \mathrm{~kg} /$ día y finalmente la R1 presentó una menor ganancia de peso diario con un valor de $0.18 \mathrm{~kg} /$ día.

\section{Cuadro No 37}

Promedio del incremento de peso diario (kg) por repeticiones des-

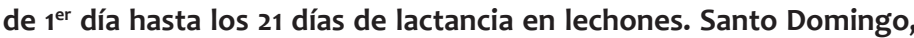
2007.

\begin{tabular}{|c|c|c|c|}
\hline Repeticiones & $\begin{array}{c}\text { Incremento de peso } \\
\text { total }(\mathbf{k g})\end{array}$ & $\begin{array}{c}\text { Incremento de } \\
\text { peso diario (kg) }\end{array}$ & Rangos \\
\hline 2 & 4,10 & 0,21 & $\mathrm{a}$ \\
4 & 4,00 & 0,20 & $\mathrm{a}$ \\
5 & 3,55 & 0,18 & $\mathrm{a}$ \\
3 & 3,73 & 0,18 & $\mathrm{a}$ \\
1 & 3,64 & 0,18 & $\mathrm{a}$ \\
\hline
\end{tabular}

Del $21^{\text {avo }}-45^{\text {avo }}$ día de vida en lechones

Interpretando los resultados del análisis estadístico de varianza para el incremento de peso desde 21 a 45 días de nacido en lechones, se determinó que existieron diferencias altamente significativas entre tratamientos pero no para repeticiones. Por lo cual se acepta la hipótesis alternativa que enuncia que la utilización de balanceados a base de harinas de plátano y palmito si incidirá significativamente en 
la ganancia de peso en la etapa inicial en lechones.

Analizadas las comparaciones ortogonales, se observó que entre el T1 vs. T2, T3 se presentaron diferencias estadísticas significativas y al comparar el T2 vs. T3 dichas diferencias fueron altamente significativas.

El coeficiente de variación para este periodo de evaluación fue de $14.96 \%$, con lo que se garantiza que la investigación ha sido bien concluida de conformidad con los datos reportados.

\section{Cuadro No 38}

Análisis de varianza del incremento de peso diario en lechones desde el $21^{\circ}$ a $45^{\circ}$ días de evaluación.

\begin{tabular}{|l|l|l|l|l|l|}
\hline \multicolumn{1}{|c|}{ F.V. } & \multicolumn{1}{c|}{ GL } & SC & CM & \multicolumn{1}{|c|}{ F } & Valor $\mathbf{P}$ \\
\hline Tratamientos & 2 & 0,03 & 0,01 & 9,39 & $0,0080 * *$ \\
T1 vs. T2,T3 & 1 & 0,01 & 0,01 & 7,49 & $0,0256 *$ \\
T2 vs. T3 & 1 & 0,02 & 0,02 & 11,29 & $0,0099 * *$ \\
REPETICIONES & 4 & 0,01 & 0 & 1,25 & 0,3657 ns \\
ERROR & 8 & 0,01 & 0 & & \\
TOTAL & 14 & 0,04 & & & \\
\hline C.V. $\%$ & 14,96
\end{tabular}

** altamente significativo; * significativo; ns: no significativo.

Se aprecia que los promedios de incrementos de pesos obtenidos por tratamientos mediante prueba de significación de rangos múltiples de Tukey al 5 \%, en el cual se detectó dos rangos estadísticos. En el primer rango (a) se colocó el T1 (B. comercial) con el mayor incremento de peso ( $0.28 \mathrm{~kg} /$ día) y en el segundo rango (b) se ubicaron los tratamientos 3 (B. H. palmito) y 2 (B. H. plátano) con incrementos promedios de 0.27 y $0.19 \mathrm{~kg} /$ día respectivamente.

\section{Cuadro No 39}

Promedio del incremento de peso diario $(\mathrm{kg})$ por tratamientos desde $21^{\circ}$ día hasta los $45^{\circ}$ días de lactancia en lechones. Santo Domingo, 2007.

\begin{tabular}{|l|c|c|c|}
\hline \multicolumn{1}{|c|}{ Tratamientos } & $\begin{array}{c}\text { Incremento de peso } \\
\text { total }(\mathbf{k g})\end{array}$ & $\begin{array}{c}\text { Incremento de peso } \\
\text { diario }(\mathbf{k g})\end{array}$ & Rangos \\
\hline 1 (B. comercial) & 6,77 & 0,28 & $\mathrm{a}$ \\
3 (B. H. palmito) & 6,40 & 0,27 & $\mathrm{~b}$ \\
2 (B. H. plátano) & 4,52 & 0,19 & $\mathrm{~b}$ \\
\hline \multicolumn{2}{|l|}{ Letras distintas indican diferencias significativas $(p<=0,05)$} \\
\hline
\end{tabular}

Los promedios de incrementos de pesos analizados mediante prueba de significación de Tukey al $5 \%$, se puede observar en el cuadro, en el cual no se detectaron rangos estadísticos diferentes entre repeticiones. Numéricamente la R3 tuvo un mayor incremento de peso con un promedio de $0.28 \mathrm{~kg} /$ día ( $5.37 \mathrm{~kg}$ ) y la R2 presentó una la menor ganancia diaria con un valor de $0.22 \mathrm{~kg} /$ día.

\section{Cuadro No 40}

Promedio del incremento de peso diario $(\mathrm{kg})$ por repeticiones desde $21^{\circ}$ día hasta los $45^{\circ}$ días de lactancia en lechones. Santo Domingo, 2007.

\begin{tabular}{|c|c|c|c|}
\hline Repeticiones & $\begin{array}{c}\text { Incremento de } \\
\text { peso total }(\mathrm{kg})\end{array}$ & $\begin{array}{c}\text { Incremento de peso } \\
\text { diario }(\mathrm{kg})\end{array}$ & Rangos \\
\hline 3 & 5,37 & 0,28 & $\mathrm{a}$ \\
5 & 5,74 & 0,26 & $\mathrm{a}$ \\
4 & 6,16 & 0,24 & $\mathrm{a}$ \\
1 & 6,68 & 0,23 & $\mathrm{a}$ \\
2 & 5,54 & 0,22 & $\mathrm{a}$ \\
\hline
\end{tabular}

\section{- Peso de lechones al destete}

En el cuadro anterior, se puede apreciar el análisis estadístico de varianza para el peso de lechones al destete en el cual se pudo observar que no existieron diferencias significativas entre tratamientos y repeticiones. 
Además en este mismo cuadro se aprecian las comparaciones ortogonales realizadas entre el T1 vs. T2, T3 y el T2 vs. T3; en las cuales se pudo observar que no se presentaron diferencias estadísticas.

El coeficiente de variación para este periodo de evaluación para la variable fue de $14.02 \%$, lo que determina que la investigación ha sido adecuadamente concluida de conformidad con los datos reportados.

\section{Cuadro No 41}

Análisis de varianza para el peso de los lechones al destete.

\begin{tabular}{|l|l|l|l|l|l|}
\hline \multicolumn{1}{|c|}{ F.V. } & \multicolumn{1}{c|}{ GL } & \multicolumn{1}{c|}{ SC } & \multicolumn{1}{c|}{ CM } & \multicolumn{1}{c|}{ F } & \multicolumn{1}{c|}{ Valor $\mathbf{P}$} \\
\hline Tratamientos & 2 & 20,87 & 10,43 & 4,29 & 0,0543 ns \\
T1 vs. T2,T3 & 1 & 8,12 & 8,12 & 3,34 & 0,1052 ns \\
T2 vs. T3 & 1 & 12,75 & 12,75 & 5,24 & 0,0514 ns \\
Repeticiones & 4 & 3,04 & 0,76 & 0,31 & 0,8621 ns \\
Error & 8 & 19,47 & 2,43 & & \\
Total & 14 & 43,38 & & & \\
\hline C.V. \% & 14,02 \\
\hline
\end{tabular}

** altamente significativo; * significativo; ns: no significativo.

La prueba de significación de rangos múltiples de Tukey al $5 \%$, no detectaron rangos estadísticos diferentes entre tratamientos. Numéricamente el T1 (Balanceado comercial) tuvo un mayor incremento de peso con un promedio de $12.17 \mathrm{~kg}$ y finalmente el tratamiento 2 (B. H. plátano) presentó la menor ganancia diaria con un valor de $9.48 \mathrm{~kg}$. (Cuadro No 26).

\section{Cuadro No 42}

Promedio de peso $(\mathrm{kg})$ de lechones al destete por tratamientos. Santo Domingo, 2007.

\begin{tabular}{|l|c|c|c|}
\multicolumn{1}{|c|}{ Tratamientos } & $\begin{array}{c}\text { Incremento de peso } \\
\text { total }(\mathrm{kg})\end{array}$ & $\begin{array}{c}\text { Incremento de peso } \\
\text { diario }(\mathrm{kg})\end{array}$ & Rangos \\
\hline 1 (B. comercial) & 6,77 & 0,28 & $\mathrm{a}$ \\
3 (B. H. palmito) & 6,40 & 0,27 & $\mathrm{~b}$ \\
2 (B. H. plátano) & 4,52 & 0,19 & $\mathrm{~b}$ \\
\hline \multicolumn{2}{|l|}{ Letras distintas indican diferencias significativas $(p<=0,05)$} \\
\hline
\end{tabular}

Se puede observar los promedios de incrementos de pesos analizados mediante prueba de significación de Tukey al 5 \%, en el cual no se detectaron rangos estadísticos diferentes entre repeticiones. Numéricamente la R3 tuvo un mayor incremento de peso con un promedio de $11.96 \mathrm{~kg}$ y finalmente la R1 presentó una menor de peso con un valor de $10.67 \mathrm{~kg}$.

\section{Cuadro No 43}

Promedio de peso (kg) de lechones al destete por repeticiones. Santo Domingo, 2007.

\begin{tabular}{|c|c|c|}
\hline Tratamientos & Peso total $(\mathrm{kg})$ & Rangos \\
\hline 3 & 11,96 & $\mathrm{a}$ \\
5 & 11,12 & $\mathrm{a}$ \\
4 & 11,09 & $\mathrm{a}$ \\
2 & 10,80 & $\mathrm{a}$ \\
1 & 10,67 & $\mathrm{a}$ \\
\hline \multicolumn{2}{|c|}{ Letras distintas indican diferencias significativas $(p<=0,05)$} \\
\hline
\end{tabular}

\section{Gráfico No 5}

Peso de lechones al destete con la utilización de balanceado a base de harinas de plátano y palmito. Santo Domingo, 2007.

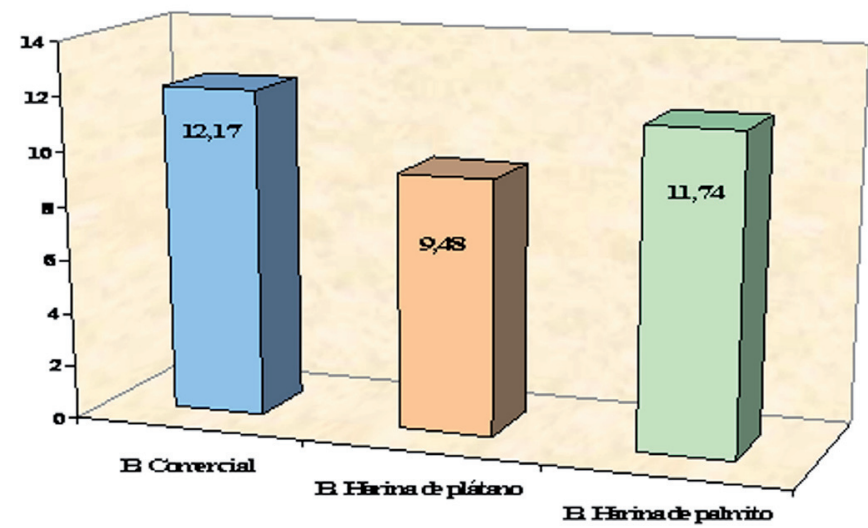

Los datos en el gráfico permite apreciar que los mayores pesos 
logrados pertenecieron al testigo con $12.17 \mathrm{~kg}$, seguido del tratamiento en que se alimentó a los lechones con concentrado a base de harina de palmito con promedios de $11.74 \mathrm{~kg}$ siendo estadísticamente similar a los demás tratamientos; de igual manera estos tratamientos lograron los mayores incrementos de pesos con promedios de 6.77 y 6.40 kg respectivamente.

Durante las tres primeras semanas de vida de los lechones, los resultados obtenidos estadísticamente, no demostraron la existencia de un tratamiento que este por encima de los demás, esto se debió a que durante este lapso de tiempo la alimentación de los lechones consistió únicamente de la leche producida por la madre, el incremento de peso en los lechones durante las tres primeras semanas de vida tuvo como factor determinante la alimentación de la madre para la obtención de estos resultados.

Los valores obtenidos anteriormente son similares a los resultados emitidos por López, E. (2008), quien reporto un incremento diario de 0,27 kg/día en cinco semanas de evaluación realizando un manejo tradicional (calefacción, uso de cortinas, alimentación tradicional de la cerda y alimentación ad libitum para lechones), la presente investigación alcanzó un incremento con el mejor tratamiento (testigo) de 0,28 kg/día en 45 días de evaluación efectuando un manejo tradicional en la cerda y su camada, pero diferenciado en la alimentación de los mismos.

Es pertinente indicar que en la investigación, numéricamente las camadas testigo obtuvieron un mayor incremento de peso, reportando una diferencia de 0,04 kg con las camadas del tratamiento plátano, quienes fueron las que registraron el menor incremento de peso durante ese periodo de evaluación, pero como se mencionó anteriormente la alimentación de la madre jugó un papel preponderante.

Posteriormente a partir de los 21 a 45 días de edad en los lechones, el incremento de peso se vio influenciado por dos factores, el primero continuó siendo la leche de la cerda y se añadió un factor que fue gravitante en la obtención del peso de lechones al destete, este factor fue la alimentación de la camada según el tratamiento, cabe recalcar que los más interesante en esta parte de la investigación fue el aprovechamiento de los rechazos de plátano o palmito procesados en forma de harina, que constituyeron materia prima para la elaboración de las dietas para alimentar a los lechones.

PRONACA, indica que obtiene pesos de $13.34 \mathrm{~kg} / \mathrm{lechón}$, con un incremento de peso de $7,80 \mathrm{~kg}$ a la edad de 45 días, en la investigación con los tratamientos 2 (harina de plátano) y 3 (harina de palmito), se obtuvo pesos de 9,48 y 11,74 kg/lechón con un incremento total de 4,52 y $6,40 \mathrm{~kg}$ respectivamente, esto quiere decir que se obtuvo pesos situados en los rangos adecuados para destetar a los lechones, añadiendo una característica particular que fue la iniciación en la alimentación sólida a los lechones combinada con la alimentación a base de leche, de esta manera se disminuyó en gran medida el estrés que se ocasiona con el cambio de alimentación en el destete.

\section{- Peso de cerdas al final de etapa de lactancia}

En el cuadro No 28, (página 46), se observa los resultados del análisis de varianza realizado para esta variable, en el cual, se pudo determinar que existieron diferencias significativas entre tratamientos, al igual que entre repeticiones. Por lo cual se acepta la hipótesis alternativa que enuncia que la utilización de rechazos de plátano o palmito más suplemento proteico en la alimentación de cerdas, si incidirá significativamente en el peso en la etapa de lactancia.

Interpretando las comparaciones ortogonales, se observó que entre el T1 vs. T2, T3 se presentaron diferencias estadísticas altamente significativas y al comparar el T2 vs. T3 no se detectaron variaciones estadísticas.

El coeficiente de variación para esta variable estudiada fue de $12.40 \%$, con lo que se garantiza que la investigación ha sido bien concluida de conformidad con los datos reportados. 


\section{Cuadro 44}

Análisis de varianza para el peso de cerda al final de la etapa de lactancia.

\begin{tabular}{|l|l|l|l|l|ll|}
\hline F.V. & GL & SC & CM & F & Valor P & \\
\hline Tratamientos & 2 & 3352,13 & 1676,07 & 5,70 & 0,028 & $*$ \\
T1 vs. T2,T3 & 1 & 3349,63 & 3349,63 & 11,40 & 0,009 & $* *$ \\
T2 vs. T3 & 1 & 2,50 & 2,50 & 0,01 & 0,928 & ns \\
Repeticiones & 4 & 7331,60 & 1832,90 & 6,24 & 0,014 & $*$ \\
Error & 8 & 2351,20 & 293,90 & & & \\
Total & 14 & 13034,93 & & & & \\
\hline C.V. \% & 12,40 \\
\hline
\end{tabular}

** altamente significativo; * significativo; ns: no significativo.

Los promedios de pesos de cerdas al final de la etapa de lactación obtenidos por tratamientos mediante prueba de significación de rangos múltiples de Tukey al 5 \%, como se observa en el cuadro No 29 (página 40), se detectó dos rangos estadísticos. En el primero (a) se colocó el T1 (B. comercial) con el mayor peso promedio de cerdas (159,4 kg) y el T3 (Palmito) con $128.20 \mathrm{~kg}$; ocupando el segundo rango (b) se ubicó el T2 (plátano) con un promedio de 127.20 kg.

\section{Cuadro No 45}

Promedio de peso $(\mathrm{kg})$ por tratamientos para el peso de cerdas al final de la etapa de lactancia. Santo Domingo, 2007.

\begin{tabular}{|l|c|c|}
\hline \multicolumn{1}{|c|}{ Tratamientos } & Peso total (kg) & Rangos \\
\hline 1 (B. comercial) & 159,40 & a \\
3 (Palmito) & 128,20 & a \\
2 (Plátano) & 127,20 & $\mathrm{~b}$ \\
\hline \multicolumn{2}{|c|}{ Letras distintas indican diferencias significativas $(p<=0,05)$} \\
\hline
\end{tabular}

Los promedios de peso de cerda al final de la etapa de lactación por repeticiones, analizados mediante prueba de significación de Tukey al $5 \%$, permitieron observar, (cuadro No 29, página 46), en el cual se detectaron rangos estadísticos diferentes. Ubicado en el $1^{\text {er }}$ rango (a) se encontró a la R4 con el mayor peso promedio por cerda con $169.67 \mathrm{~kg}$ y en el $2^{\text {do }}$ rango se encontró a la R2 con 102.67 kg, sien- do este último valor, el menor peso logrado.

\section{Cuadro 46}

Promedio de peso diario $(\mathrm{kg})$ por repeticiones para el peso de cerdas al final de la etapa de lactancia. Santo Domingo, 2007

\begin{tabular}{|c|c|c|}
\hline \multirow{2}{*}{ Tratamientos } & Peso total $\mathbf{k g})$ & Rangos \\
\hline 4 & 169,67 & $\mathrm{a}$ \\
1 & 148,33 & $\mathrm{ab}$ \\
3 & 141,33 & $\mathrm{ab}$ \\
5 & 129,33 & $\mathrm{ab}$ \\
2 & 102,67 & $\mathrm{~b}$ \\
\hline
\end{tabular}

Letras distintas indican diferencias significativas
$(p<=0,05)$

\section{Gráfico N 6}

Peso de cerdas al final de la etapa de lactancia con la utilización de rechazos de plátano ó palmito más suplemento proteico. Santo Domingo, 2007.

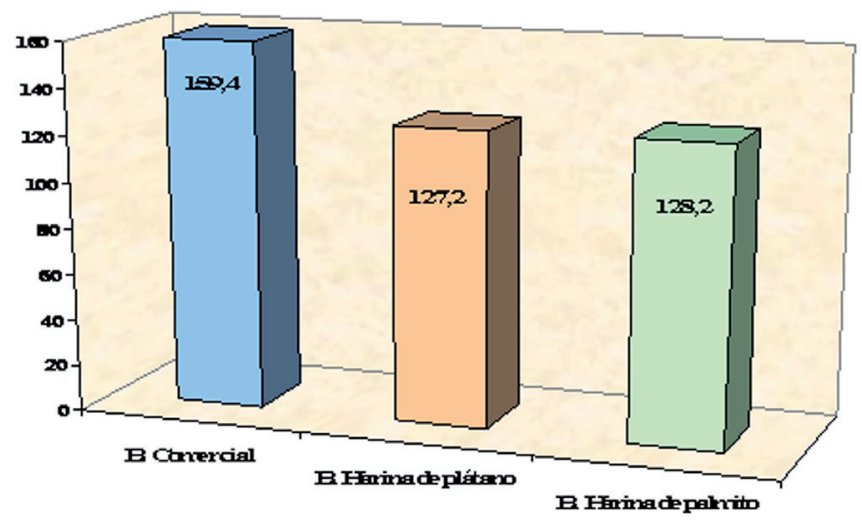

Conversión alimenticia en lechones desde el $21^{\circ}$ al $45^{\circ}$ día

A través de los resultados del análisis de varianza para la conversión alimenticia en lechones a partir del $21^{\text {avo }}$ al $45^{\text {avo }}$ día, se pudo determinar que existieron diferencias significativas entre tratamientos, al igual que entre repeticiones. Por lo cual se acepta la hipótesis alternativa que enuncia que la utilización de rechazos de plátano y palmito 
más un suplemento proteico en la alimentación de cerdas, si incidirá significativamente en el peso en la etapa de lactancia.

Interpretando las comparaciones ortogonales, se observó que entre el T1 vs. T2, T3 se presentaron diferencias estadísticas altamente significativas y al comparar el T2 vs. T3 no se detectaron variaciones estadísticas.

El coeficiente de variación para esta variable estudiada fue de $18.20 \%$, con lo que se garantiza que la investigación ha sido bien concluida de conformidad con los datos reportados.

\section{Cuadro No 47}

Análisis de varianza para la conversión alimenticia en lechones desde el $21^{\circ}$ al $45^{\circ}$ día.

\begin{tabular}{|l|l|l|l|l|ll|}
\hline F.V. & GL & SC & CM & F & Valor P & \\
\hline Tratamientos & 2 & 0,68 & 0,34 & 12,4 & 0,0035 & $* *$ \\
T1 vs. T2,T3 & 1 & 0,45 & 0,45 & 16,35 & 0,0037 & $* *$ \\
T2 vs. T3 & 1 & 0,23 & 0,23 & 8,46 & 0,0196 & $*$ \\
Repeticiones & 4 & 0,21 & 0,05 & 1,89 & 0,2062 & ns \\
Error & 8 & 0,22 & 0,03 & & & \\
Total & 14 & 1,10 & & & & \\
\hline C.V. \% & 18.20 & & & & \\
\hline
\end{tabular}

**altamente significativo; *significativo; ns: no significativo. C.V = corregido $V x$

En el cuadro No 32, página 43 se observan los promedios de conversión alimenticia desde el $21^{\text {avo }}$ al $45^{\text {avo }}$ día en lechones obtenidos por tratamientos mediante prueba de significación de rangos múltiples de Tukey al $5 \%$, en el cual se detectó dos rangos estadísticos. En el primer rango (a) se colocó el T1 (B. comercial) con el más eficiente índice de conversión (0.46); es decir que para producirse un kg de carne en este tratamiento se suministró $0.46 \mathrm{~kg}$ de alimento. El T3 (B. H. palmito) y T2 (B. H. plátano) ocupan el segundo rango (b) con índices de 0.78 y 1.46 .

\section{Cuadro No 48}

Promedio de conversión alimenticia en lechones desde el $21^{\circ}$ al $45^{\circ}$ día. Santo Domingo, 2007.

\begin{tabular}{|l|l|l|}
\multicolumn{1}{|c|}{ Tratamientos } & \multicolumn{1}{|c|}{ Peso total (kg) } & Rangos \\
& & \\
\hline 1 (B. comercial) & 0,46 & $\mathrm{a}$ \\
3 (Palmito) & 0,78 & $\mathrm{~b}$ \\
2 (Plátano) & 1,46 & $\mathrm{~b}$ \\
\hline Letras distintas indican diferencias significativas $(p<=0,05)$ \\
\hline
\end{tabular}

Los promedios de peso de diario $(\mathrm{kg})$ en lechones desde el $21^{\circ}$ al $45^{\circ}$ día por repeticiones analizados mediante prueba de significación de Tukey al 5 \%, se puede observar en el cuadro 33, en el cual se detectaron rangos estadísticos diferentes. Ubicado en el $1^{\text {er }}$ rango (a) se encontró a la R4 con el mayor peso promedio por cerda con 169.67 kg y en el $2^{\circ}$ rango se encontró a la R2 con $102.67 \mathrm{~kg}$, siendo este último valor, el menor peso logrado.

\section{Cuadro No 49}

Promedio de peso diario $(\mathrm{kg})$ en lechones desde el $21^{\circ}$ al $45^{\circ}$ día por repeticiones. Santo Domingo, 2007.

\begin{tabular}{|c|c|c|}
\hline Repeticiones & Peso total (kg) & Rangos \\
\hline 4 & 0,66 & $\mathrm{a}$ \\
3 & 0,72 & $\mathrm{ab}$ \\
5 & 0,75 & $\mathrm{ab}$ \\
1 & 1,12 & $\mathrm{ab}$ \\
2 & 1,25 & $\mathrm{~b}$ \\
\hline \multicolumn{2}{|c|}{ Letras distintas indican diferencias significativas $(p<=0,05)$} \\
\hline
\end{tabular}




\section{Gráfico No 7}

Conversión alimenticia desde el $21^{\circ}$ al $45^{\circ}$ día en etapa inicial en lechones. Santo Domingo, 2007.

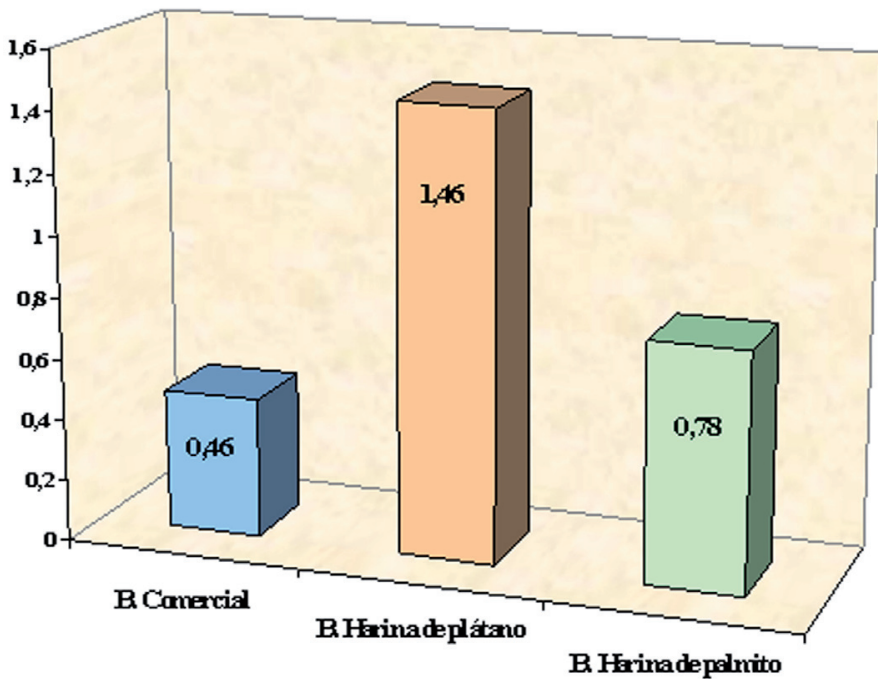

- Mortalidad

En el cuadro No 34, se puede apreciar que el T1 (testigo), tuvo 53 lechones nacidos vivos siendo la mayor cantidad de lechones obtenidos por tratamiento, seguido muy de cerca por el T2 (plátano) y el T3 (palmito) con 43 y 34 lechones respectivamente, en cuanto al número de lechones muertos antes del destete el T2 presento la menor cantidad de bajas con tan solo 2 lechón muertos, el T1 y el T2 reportaron 3 lechones muertos respectivamente y en el porcentaje de mortalidad de lechones por tratamiento, el T3 presento el mayor porcentaje de mortalidad con 8,8\%, el T1 y el T2 exhibieron un menor porcentaje de con $6,0 \%$ y $4,7 \%$ respectivamente.

\section{Cuadro No 50}

Porcentaje de mortalidad en lechones desde el 1 $^{\text {er }}$ día de nacidos hasta el destete.

\begin{tabular}{|c|c|c|c|c|}
\hline Tratamiento & $\begin{array}{c}\text { Número de } \\
\text { lechones } \\
\text { nacidos vivos }\end{array}$ & $\begin{array}{c}\text { Número de } \\
\text { lechones } \\
\text { muertos antes } \\
\text { destete }\end{array}$ & $\begin{array}{c}\text { Número de } \\
\text { lechones } \\
\text { destetados }\end{array}$ & $\begin{array}{c}\text { Porcentaje de } \\
\text { Mortalidad }\end{array}$ \\
\hline T1 (testigo) & 53 & 3 & 50 & 6,0 \\
\hline T2 (plátano) & 45 & 2 & 43 & 4,7 \\
\hline T3 (palmito) & 37 & 3 & 34 & 8,8 \\
\hline
\end{tabular}

Gráfico N 8

Porcentaje de mortalidad en lechones por tratamiento desde el 1 $^{\text {er }}$ día de nacidos hasta el destete. Santo Domingo, 2007.

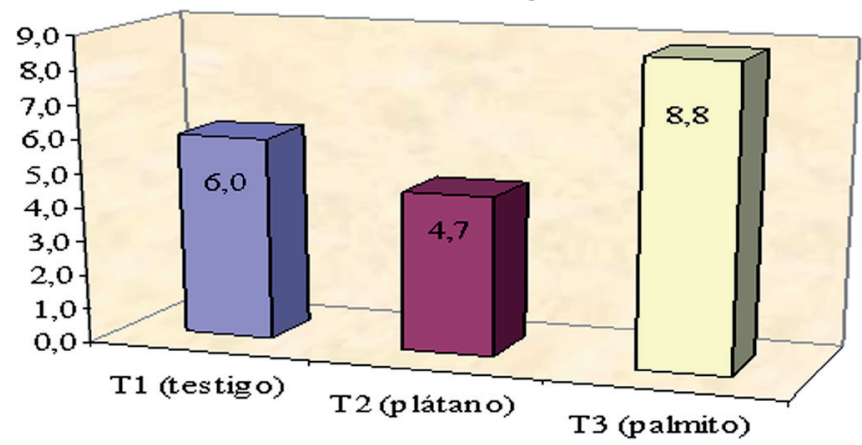

Según NIELSEN (1974), citado por López, E. (2008), señala que la mortalidad en camadas comerciales de 8 lechones es de un 14,3\%, que corresponde a 1,14 lechones muertos; en la investigación el numero de lechones por camada no fue homogéneo debido a la presencia de parvo virosis en la piara, por lo tanto la mortalidad presentada durante la lactancia es variable.

\section{Conclusiones y Recomendaciones}

\section{Conclusiones}

\section{- Gestación}

De acuerdo a los resultados obtenidos en el experimento, se puede indicar las siguientes conclusiones:

1. El T2 (suplemento proteico + palmito), presentó mejores resultados en todas las variables evaluadas en cerdas gestantes, excepto en peso promedio de lechones al nacimiento, donde el testigo (Balanceado comercial) mostró mejores resultados.

2. El mejor incremento de peso en cerdas durante la gestación se registró con el T2 (suplemento proteico + palmito) con 0,62 kg de ganancia de peso/día, mientras que el testigo (Ba- 
lanceado comercial), mostró 0,58kg/día.

3. Para la variable peso post parto, los mejores resultados se obtuvieron en el T2 (suplemento proteico + palmito) con 172 kg.

4. El rendimiento en cuanto al peso promedio de lechones al nacimiento fue mejor para el tratamiento testigo (Balanceado comercial), con un valor de $1547,45 \mathrm{~g}$, lo que demuestra que este tipo de alimentos está dirigido al peso del lechón.

5. La conversión alimenticia durante la gestación, presento mayor eficiencia el T2 (suplemento proteico + palmito), con 2,99 con una diferencia de 0,06 y 1,02 entre los tratamientos T3 (Balanceado comercial) y T1 (suplemento proteico + plátano).

6. Al analizar los costos de producción los tratamientos que presentaron menores costos son los tratamientos T1 (suplemento proteico + plátano) y T2 (suplemento proteico + palmito).

\section{- $\quad$ Lactancia}

De acuerdo a los resultados obtenidos en el experimento, se puede indicar las siguientes conclusiones:

1. Estadísticamente no hubo diferencias significativas entre tratamientos parar el incremento de peso en lechones durante los primeros 21 días de vida con una alimentación basada en leche materna. A partir de los 21 hasta los 45 días de edad el incremento de peso en los lechones estuvo influenciado directamente por el alimento que se les ofreció más la leche de la cerda; el mejor incremento de peso lo obtuvo el T1 (testigo) con $0.28 \mathrm{~kg} /$ día, seguido por el T3 (harina de palmito) con $0.27 \mathrm{~kg} /$ día y finalmente el T2 (harina de plátano) mostró un bajo incremento de peso con $0.19 \mathrm{~kg} / \mathrm{dí}$.
2. En cuanto al peso de los lechones al destete estadísticamente no hubo diferencias significativas, mientras que numéricamente los resultados se presentaron favorables para el T1 (testigo) y el T3 (harina de palmito) con pesos promedios al destete de 12.17 y $11.74 \mathrm{~kg}$ respectivamente; el T2 (harina de plátano) presentó un peso promedio de 9.48 kg; valor que muestra una diferencia de $2.69 \mathrm{~kg}$ con el mejor tratamiento. Dicho esto, los pesos de lechones al destete obtenidos en la investigación fueron excelentes, ya que están situadas en el rango de 9.87 a $10.20 \mathrm{~kg}$ en 6 semanas de edad presentados por AGRAZ, A y FLORES, J. (1986).

3. El peso de cerdas al destete, presentó estadísticamente diferencias significativas entre tratamientos mostrando el mejor resultado con un peso promedio de $159.40 \mathrm{~kg}$ para el T1 (testigo); el T2 (plátano) y T3 (palmito) demostraron ser tratamientos deficientes, donde se observó pesos promedios 127.20 y $128.20 \mathrm{~kg}$ respectivamente.

4. La conversión alimenticia de lechones fue evaluada a partir de los 21 días de edad, ya que para este lapso de tiempo se procedió a alimentar a los lechones con concentrados según el tratamiento; la mejor conversión alimenticia la presentó el T1 (testigo) con un valor de 0.46; es decir que por cada dólar kg de alimento suministrado a los lechones esto lo convertían en un kg de carne, el T3 (palmito) presentó una conversión de 0.78 y finalmente el T2 (plátano) mostró una deficiente conversión alimenticia con 1.46.

5. La mortalidad de lechones por tratamiento fue mayor para el T3 (palmito) con un porcentaje de 8.8 que numéricamente correspondió a 3 lechones muertos; el T1 (testigo) y el T2 (plátano presentaron una mortalidad de 6.0 y $4.7 \%$ respectivamente.

6. Según el análisis económico el mejor tratamiento fue el T2 
(plátano), el cual presentó un costo de producción de \$ 37.14 por lechón destetado con una relación costo - beneficio de \$1.21; es decir que por cada dólar invertido hay una ganancia de \$ 0.21; mientras que el T3 (palmito) ostentó el costo de producción más elevado de la investigación con \$ 47.23 por lechón destetado, ocasionando una pérdida de \$ 0.95 por cada dólar invertido; el T1 (testigo) mostró un costo de producción de $\$ 42.18$ con una relación costo-beneficio de $\$$ 1.07 .

\section{- $\quad$ Engorde}

1. Los mayores incrementos de peso se presentaron en el tratamiento T2 (Balanceado Comercial) con resultados en la fase de crecimiento de $0.57 \mathrm{Kg} /$ día, y en la fase de acabado con un incremento de $0.86 \mathrm{Kg} /$ día, seguido del tratamiento T1 (Suplemento proteico+ plátano) que tuvo un incremento de peso de $0.50 \mathrm{Kg} /$ día para la fase de crecimiento sin embargo en la fase de acabado el tratamiento T3 (Suplemento proteico+ palmito) obtuvo mejor resultado que el tratamiento $\mathrm{T} 1$ con un incremento de peso de $0.77 \mathrm{Kg} /$ día.

2. En la fase de acabado, la ganancia de peso, presentó diferencias estadísticas altamente significativas y, en la fase de acabado se obtuvo solo diferencias estadísticas significativas.

3. Solo en la fase de crecimiento, la conversión alimenticia, presentó diferencias estadísticas altamente significativas.

4. La mortalidad del ensayo fue del $6.7 \%$, valor distribuido entre el tratamiento T1 (Suplemento proteico+ plátano) y T3 (Suplemento proteico+ palmito).

5. Al analizar la rentabilidad, el tratamiento T3 (Suplemento proteico+ palmito) tiene el mayor beneficio-costo con 1.37 significando que por cada dólar de inversión se obtiene 0.37 centavos, mientras que el tratamiento T2 (Suplemento proteico+ plátano) obtuvo el menor $\mathrm{B} / \mathrm{C}$ de 1.20 es decir por cada dólar invertido se obtiene 0.20 centavos.

\section{Recomendaciones}

En base a los resultados obtenidos llegó a las siguientes:

1. Para reducir costos de producción en alimentación de cerdas gestantes se recomienda utilizar el T2 (suplemento proteico + palmito).

2. El uso de subproductos de plátano y palmito en la alimentación animal es recomendable para productores que explotan este tipo de cultivos ya que su disponibilidad es continua y su costo disminuirá debido a que se eliminaría el costo de transporte, especialmente para el palmito.

3. Continuar estudios con otros subproductos disponibles en la zona y comprobar su eficiencia en la alimentación porcina.

4. Para obtener buenos incrementos de peso en lechones a partir de los 21 días de edad cuando estos empiezan a recibir alimento sólido, se recomienda utilizar las dietas proporcionadas al T1 (testigo) y al T3 (palmito); las cuales presentaron una ganancia de peso promedio de 0.28 y $0.27 \mathrm{~kg} /$ día respectivamente.

5. De la misma manera para la obtención de pesos en lechones al destete situados en los rangos requeridos por el mercado, se debe utilizar preferentemente la alimentación del T1 (testigo) y T3 (palmito), de los que se obtuvo pesos promedios al destete de 12.17 y $11.74 \mathrm{~kg} /$ lechón destetado con conversiones alimenticias de 0.46 y 0.78 respectivamente.

6. Para disminuir el desgate de la cerda durante el periodo de lactancia se recomienda utilizar la alimentación proporcionada al T1 (testigo), que mostró un peso al final de la lactancia de 159.40 kg; 
pero si se requiere alimentar a las cerdas con rechazos de plátano ó palmito se recomienda modificar el horario de alimentación; es decir suministrar los $10 \mathrm{~kg}$ de rechazo de las siguientes manera: $5 \mathrm{~kg}$ en la mañana, $5 \mathrm{~kg}$ al medio día y la dosis de suplemento proteico ofrecerlo en la tarde, de esta manera la cerda lactante aprovechara de mejor manera el alimento suministrado.

7. Según el análisis económico se recomienda manejar el T2 (plátano), ya que por cada dólar invertido hay una ganancia de \$0.21.

8. Se recomienda realizar pruebas de digestibilidad de las dietas para cerdas y lechones durante la fase de lactancia para de esta manera obtener datos más exactos, ya que para el cálculo de las dietas se utilizó solamente el método del tanteo y cuadrado de Pearson.

9. Actualmente existe muy poca información acerca de este tema, y en especial de la utilización de las harinas de rechazos de plátano o palmito para alimentar a lechones lactantes, por que se recomienda realizar más investigaciones acerca del aprovechamiento de los rechazos (plátano ó palmito) en la nutrición de cerdos en la fase de lactancia.

10. La mejor manera de reducir costos de producción sin lugar a dudas es utilizar la dieta que consiste en Suplemento proteico+ Palmito, ya que si bien este tratamiento alcanzó los $80 \mathrm{~kg}$ trece días después de haber finalizado el tratamiento con balanceado comercial, en el análisis beneficio costo el tratamiento con palmito, obtuvo mayor ingreso económico.

11. Sin embargo es necesario quiero recalcar que la dieta con Suplemento proteico+ palmito fue difícil de mantener debido a que el tocón del palmito tiene un periodo en percha relativamente corto lo que limita el almacenamiento del mismo; otro limitante es que la materia prima fue difícil de obtener debido a que las empresas procesadoras de palmito lo utilizan para otros fines agrícolas (Abonos orgánicos), A pesar de esto se consiguió dos fuentes de abastecimiento de palmito pero con la limitante que estos sectores están ubicadas a dos horas de Santo Domingo, por lo que los costos de producción por concepto de transportación fueron mucho más elevados que el resto de los tratamientos, finalmente este tratamiento va dirigido a las personas que cuenten con un abastecimiento de este material en forma permanente y sobretodo que estén ubicadas cerca de los centros de acopio.

12. Implantar un sistema básico de bioseguridad, para conservar la salud de los animales de la granja porcina y los animales que estén en investigación para de esta manera evitar la alteración de resultados por agentes patógenos externos.

13. Seguir realizando investigaciones sobre el uso del tocón del palmito, en el engorde de cerdos, aumentando la proporción de este en la dieta para observar si tiene mejores resultados, y de esta manera seguir abaratando los costos de producción.

\section{Bibliografía consultada}

1. AACP, (2006). La carne de cerdo y su valor nutricional, revisado 04 de agosto de 2008, disponible en: http://www.aacporcinos.com. ar/articulos/la_carne_de_cerdo_y_su_valor_nutricional.html

2. Aguilar, J. A. (2008). Carne de cerdo ¿Es buena o mala?, revisado 04 de agosto de, disponible en: http//www.profeco.gob.mx/ revista/publicaciones/adelantos_06cerdo_ago06.pdf

3. AEBE, (2008). Asociación de exportadores de banano del ecuador, 2007, Primer trimestre del año con altibajos en el sector, consultado el 01 de Agosto del se lo encuentra en http://www. aebe.com.ec/Desktop.aspx?Id=19\&art=2224

4. Almond, G. W., (2008). College of Veterinary Medicine - North Carolina State University, How much water do pigs need?, revisado 28 de abril/08.

5. APADE, (2008). Asociación participación para el desarrollo), Plá- 
tano, consultado el 29 de Agosto/08, fuente: http://www.apades. org/cultivos/plat.htm

6. Argenti y Espinoza (FONAIAP), (2008). Alimentación alternativa para cerdos, fuente: http://www.fonaiap.gov.ve/publica/divulga/ fd61/alimen.html

7. ASPE (Asociación de porcicultores del Ecuador) (2008). Población porcícola, , fuente: http://www.aspe.org.ec/porcinos/ porcinos/112.htm

8. BORBOLLA. A, (2008). Alternativas a los costos de alimentación. Áreas para mejorar. Fuente: http://www.porcicultura.com/articul os/?seccion=nutricion\&tema=nut052

9. Campabadal, C. Conceptos importantes en la alimentación de cerdos, revisado 18 de agosto de 2008, disponible en: http://www. soyamex.com.mx/sp/Animal/lance $\% 202006 /$ cerdos/CARLOS\%20 CAMPABADAL/INTRODUCCION\%20A\%20LA\%2ONUTRICION\%20 DE\%20CERDOS.pdf

10. Clarence, M. 2000. El Manual Merck de Veterinaria. 5ta ed. Edit. Océano. Barcelona, España. Pp. 1259

11. CLAVIJO, H. (1972). Utilización de banano y plátano en la alimentación de cerdos, Seminarios sobre sistemas de producción porcina en América Latina, Palmira- Colombia, Centro internacional de Agricultura Tropical.

12. Clavijo, H; Maner, J. (1974). El uso de banano de rechazo en la alimentación de cerdos, Cali- Colombia, Centro internacional de agricultura Tropical, 20 Pg. (CIAT- Series EE no 6)

13. Church, D. y Pond, W. (1990). Fundamentos de nutrición y alimentación de animales. Trad. Por Luís Jorge Pérez. C.D.P Editorial Lisura México pp. $289-290$.

14. DAC (Dirección de Aviación Civil). (2007- 2008) Estación Meteorológica. Santo Domingo de los Colorados - Ecuador
15. ENCARTA, (2007). El cerdo, Microsoft ${ }^{\circledR}$ Encarta ${ }^{\circledR}$ 2007. $\odot 1993-$ 2006 Microsoft Corporation. Reservados todos los derechos.

16. EL UNIVERSO, (2005). Porcicultura, hacia la tecnificación. Fuente: http://archivo.eluniverso.com/2005/01/22/0001/71/ AD6A595E99694228B44C8ABD030E3006.aspx

17. ENGORMIX, (2006). Alimentación de cerdo a base de plátano, consultado el 01 de Agosto del 2008, fuente: http://www.engormix.com/alimentacion_cerdo_a_base_forumsview1709.htm

18. FAO, D15 (2008). Musa x paradisiaca L, Banano, plátano (“ Banana “, “ plantain " o " cooking banana "), fuente: http://www.fao. org/ag/aga/agap/frg/afris/espanol/document/tfeed8/Data/176. HTM

19. Garcia. A. y Martinez. R.M, (2008). Uso de follajes del plátano en la alimentación del cerdo. Fuente: http://www.sian.info.ve/porcinos/publicaciones/rccpn/rev63/RCPP63art2.htm

20. Garcia. A. (2008). Uso de residuos foliares del plátano en la alimentación del cerdo. balance de $\mathrm{N}$ y energía. Fuente: http://www. sian.info.ve/porcinos/publicaciones/rccpn/REV22/ARISTIDE.htm

21. Gispert. C. (2004) Enciclopedia practica de la agricultura y la ganadería, OCEANO grupo editorial, España, Pág. 891.

22. Garcia Chávez, F. (1985), Técnicas y practicas modernas en la cría de cerdos. $1^{\text {a }}$ edición. Editores Mexicanos Unidos. México. Págs.: 25-28-29-31.

23. Garcia Carrasco, D. (2002), Etología, manejo físico y alternativas terapéuticas en cerdos, revisado 28 de abril de 2008, disponible en: http://www.editorial-acd.com/obras\%20p\%2olectura/etologiaymanejofisico/etologiaymanejofisico.htm

24. Fraga, Fernandez - Cuevas, M. J. (1985), Alimentación de los animales mono gástricos: cerdo, conejo, aves. $1^{\text {a }}$ edición. Edit. Mundi Prensa. España. Págs.: 15-67-68 
25. INSTITUTO DE INVESTIGACIONES PORCINAS, (2004), Bananas y plátanos para alimentar cerdos: aspectos de la composición química de las frutas y de su palatabilidad. Fuente: Fuente: http:// www.cipav.org.co/RevCubana/fullart/1103/110301.doc

26. Jacome, G. (2000). Kutzu Tropical, Pueraria phaseolides, banano verde y Melaza + suplemento en la alimentación de cerdos en crecimiento y acabado. Quevedo - Ecuador.

27. LEXUR, (2007). Nuevos datos sobre el origen salvaje de los cerdos domésticos. Fuente: http://www.solociencia.com/ biologia/05042510.htm

28. Maner, J. (1970). Resumen del uso del banano en la alimentación de cerdos, Cali- Colombia, Centro internacional de agricultura tropical, 2opag.

29. MRECl, Unión Europea, (2008). La cadena de maíz, avicultura y porcicultura frente a la UE. Fuente: http://200.6.8.25/ mmrree/?q=node/ 181

30. N.C.R. (National Research Council), (1988), Necesidades nutritivas de los cerdos. Editorial Hemisferio Sur. México pp. 180-185

31. NUTRICIÓN, (2008). Valor Nutritivo Del Palmito 626. Fuente: http://www.nutricion.us/dietas/dieta/valor-nutritivo-del-palmito$626 /$.

32. Rowan, J. P.; Durrance, K. L.; Combs, G. E. y Fisher, L. Z. (2007). University of Florida, the Digestive Tract of the Pig.

33. Maggi, E. (2006), Análisis de la cadena alimentaria del porcino. Disponible en: http://www.alimentosargentinos.gov.ar/o- / revistas/r_33/cadenas/carnes_porcinos.htm

34. Mora-Delgado,, J.; Holguín, V. (2002), Opciones de ganadería en sistemas de producción campesinos de América Latina Disponible en: http://virtualcentre.org/es/enl/keynote3.htm
35. Pardo Rincón, N. A. (2007), Manual de nutrición animal. $1^{\text {a }}$ edición. Grupo Latino Editores Ltda. Bogotá, Colombia. Págs.: 408-412414-416-421-423-426-437-450-452.

36. Pelaez, M. (2004). Estudio de factibilidad para el engorde y comercialización de cerdos en pie, mediante manejo intensivo. Santo Domingo de los Colorados-Ecuador. 89p. il.

37. PRONACA, (2007). Manual de porcicultura, Quito- Ecuador, Pág $37 ; 40$.

38. Shimada. A, (2003). Nutrición animal, Edit. Trillas, México, Pág 236- 237.

39. Silva, C. E. (2004). "Bioestadística y Diseño Experimental”. (Módulo). Maestría en nutrición vegetal. Universidad Tecnológica Equinoccial. Santo Domingo de los colorados, Ecuador. 122 p.

40. Torres. C, (2002). Manual Agropecuario, Hogares juveniles campesinos, LIMERIN, Tomo I, Colombia, Pág. 143; 153.

41. UCO (Universidad de Córdoba), (2008). Historia, evolución y situación actual del cerdo Ibérico. Fuente: http://www.uco.es/organiza/departamentos/prod-animal/economia/dehesa/historia.htm

42. Vadell, A; Barlocco, N. y Garrin, D. (2003). Características de los principales componentes de los sistemas de producción de cerdos a campo en Uruguay. Instituto Nacional de tecnología Agropecuaria (INTA). Disponible http://sian.info.ve/porcinos/

43. Yanez, G. (1998). Uso de jugo de caña de azúcar para engorde y acabar los Col

\section{La Investigadora}

Ing. Diana Buitrón Marín dbuitron@ute.edu.ec

Ingeniera Agroindustrial; Universidad Tecnológica Equinoccial, 2005 Maestría en Gerencia de Negocios, Universidad Tecnológica Equinoccial 


\section{Anexos}

\section{Anexo $\mathrm{N}^{\circ}{ }_{1}$}

Sistema de marcación utilizado en la investigación, Santo Domingo de los Colorados, 2007

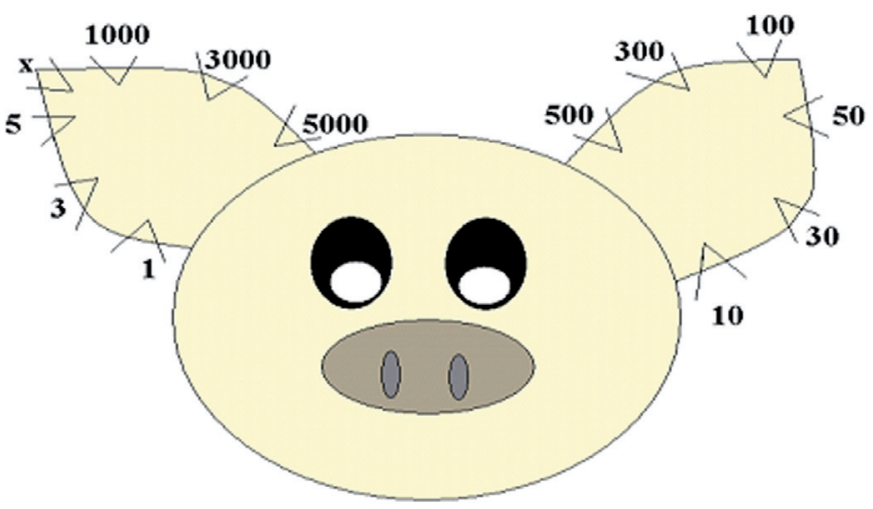

Anexo $\mathrm{N}^{\circ} 2$

Camada de 1 día de edad.

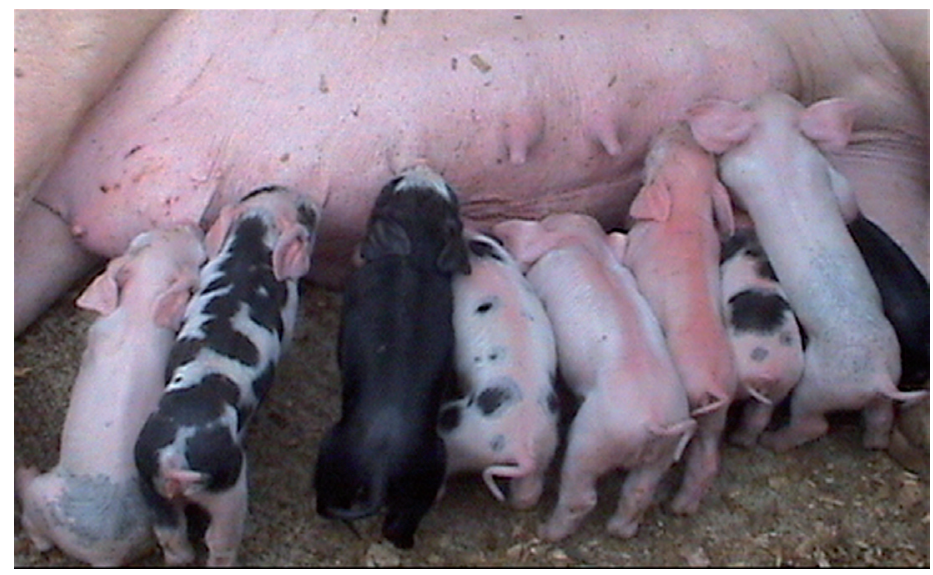

Anexo 3.

Mortalidad posparto (lechón muerto por debilidad).

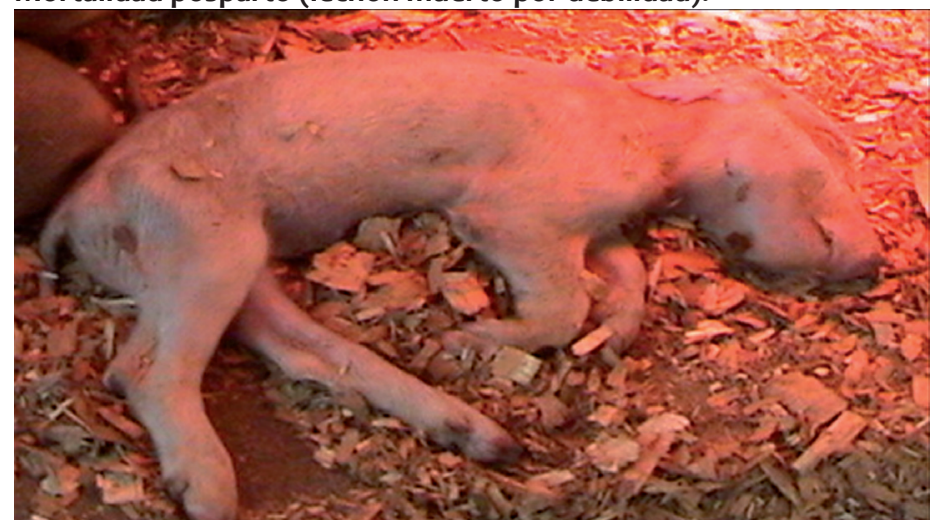

Anexo 4 .

Lechones de 35 días de edad alimentándose.

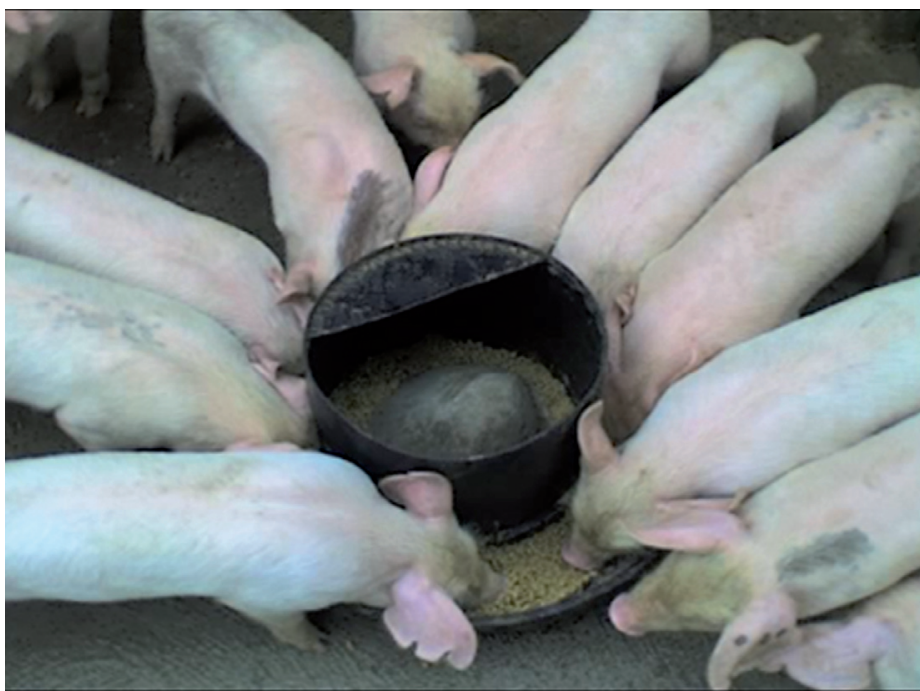

Anexo 5.

Lechón utilizando bebedero automático (chupón).

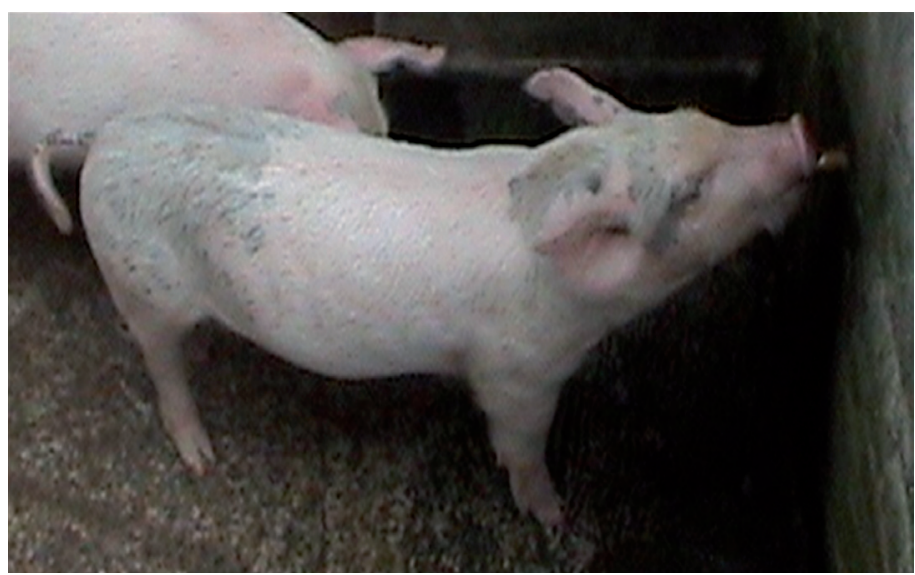

Anexo 6.

Cerda alimentándose (Tratamiento plátano).

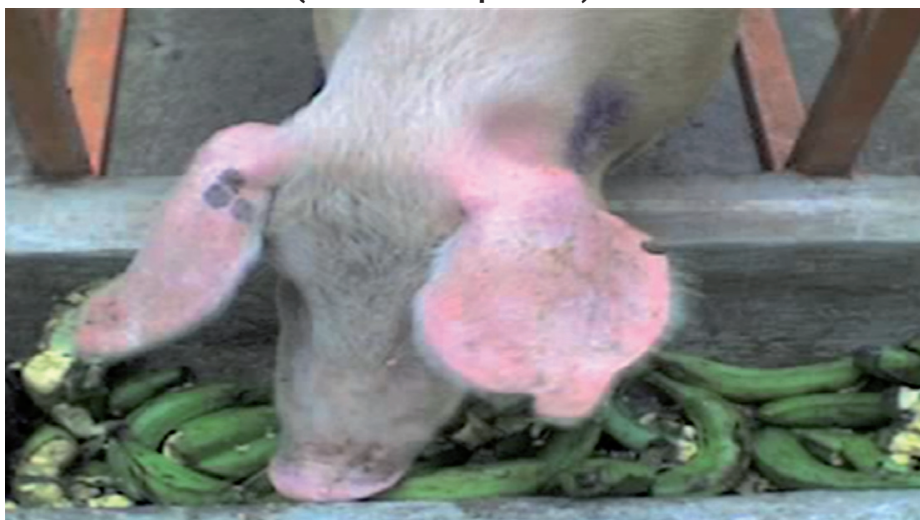




\section{Engorde}

\section{Anexo 3}

A3.1 Superior. Proteico + Plátano (45 días)

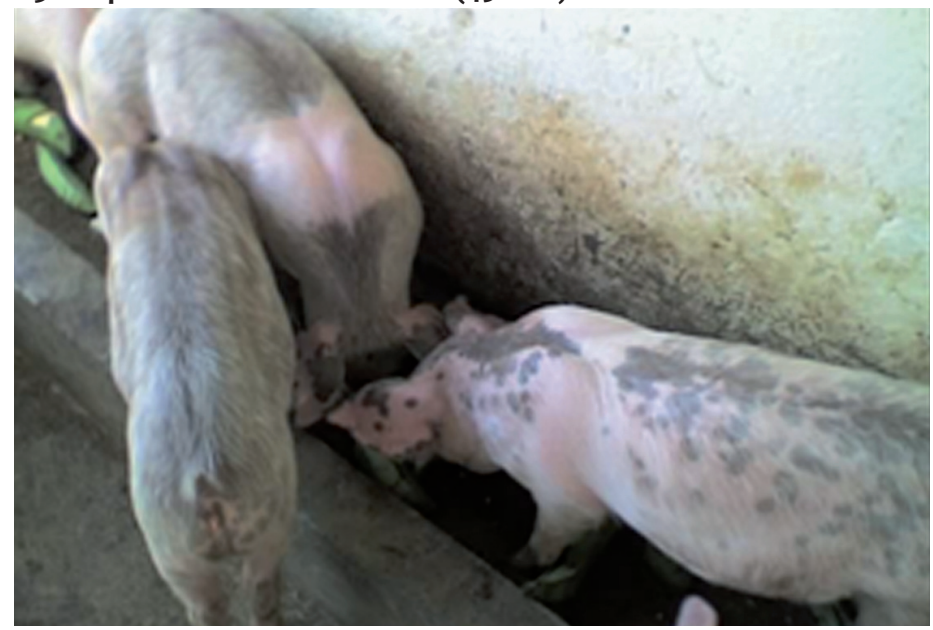

A3.2 Superior. Proteico + Palmito (45 días)

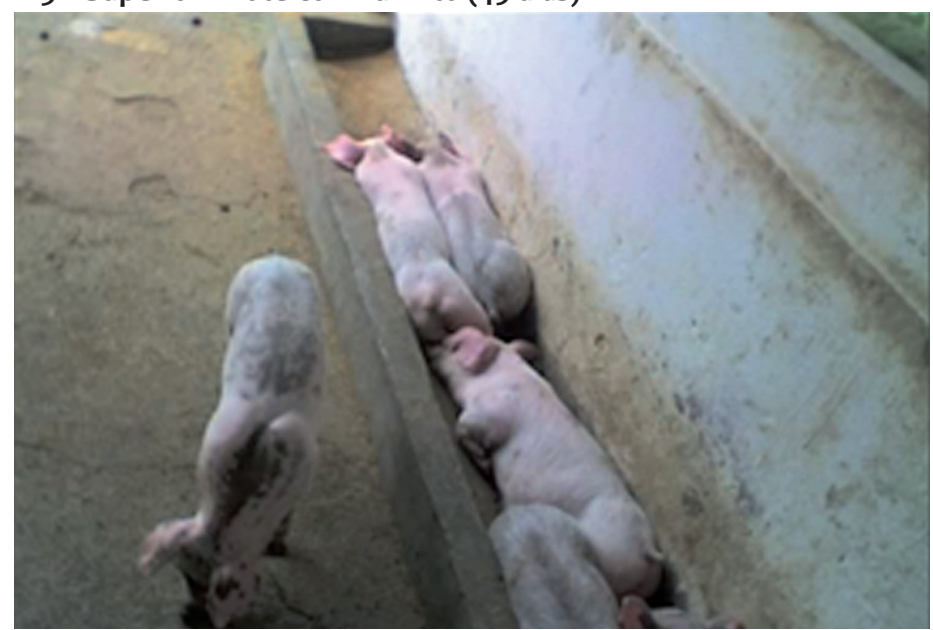

A3.3 Balanceado comercial (45 días)

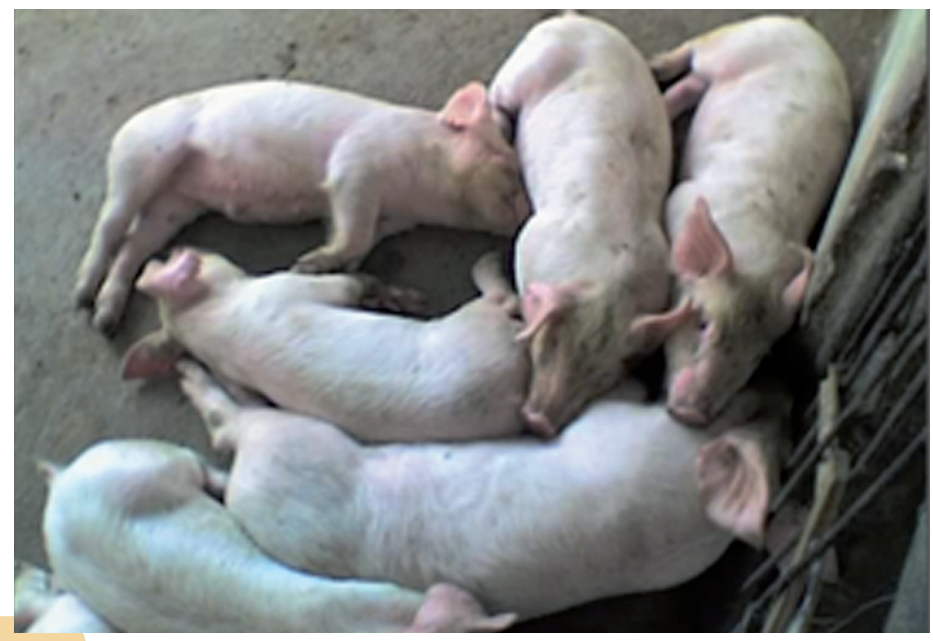

A3.4 Superior. Proteico + Plátano (102 días)
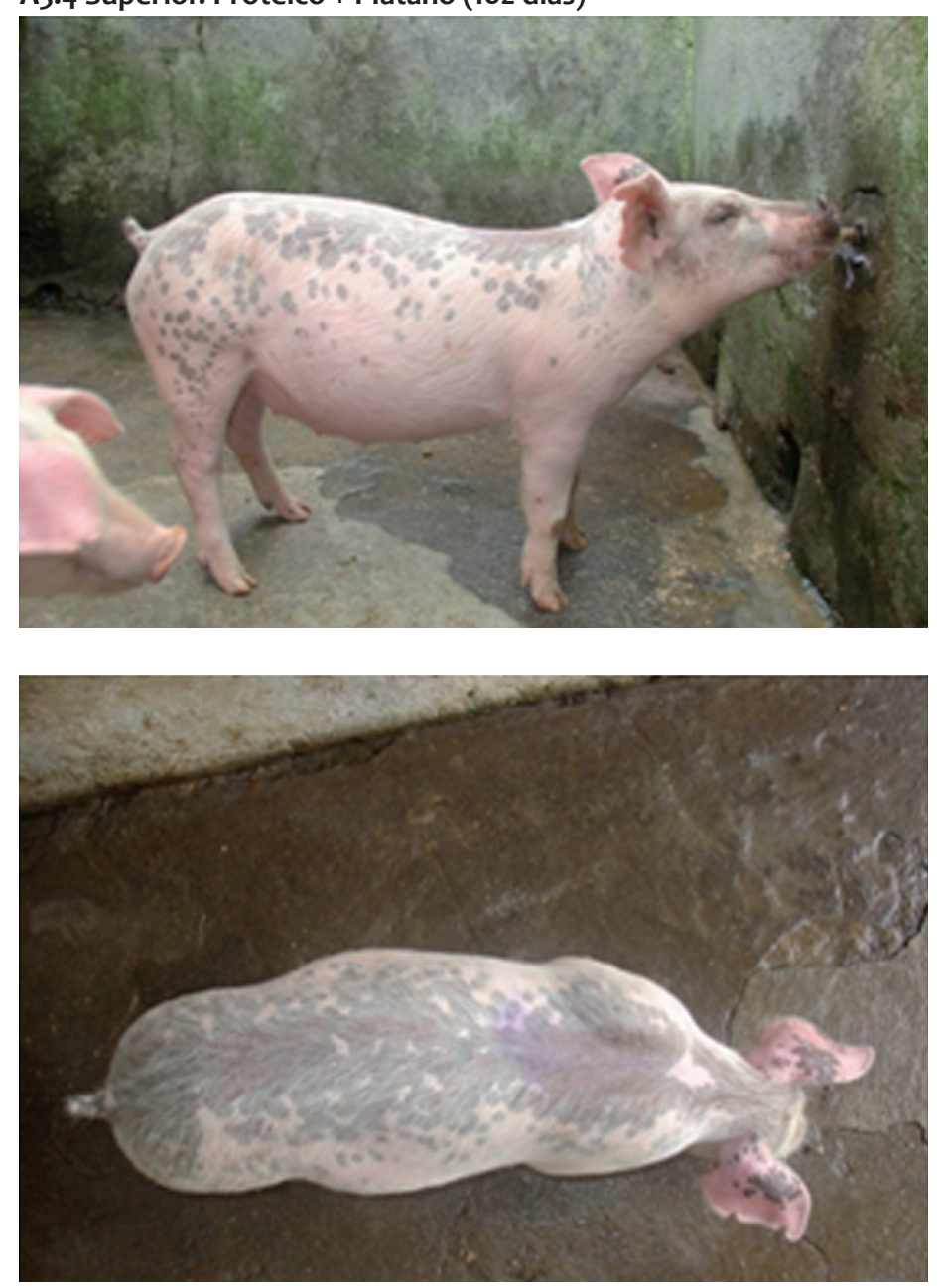

A3.5 Superior. Proteico + Palmito (102 días)

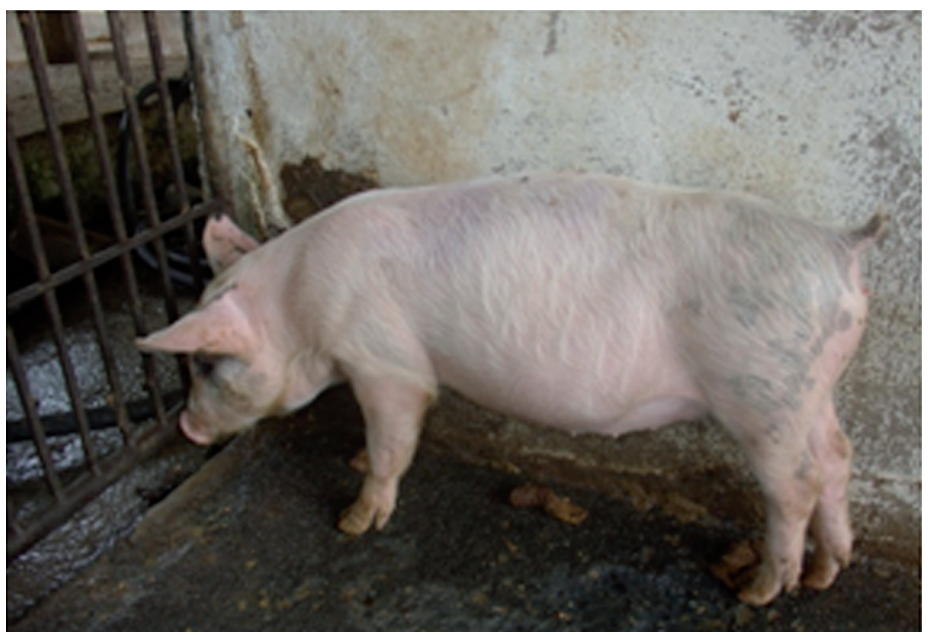

Tsafiquiew 


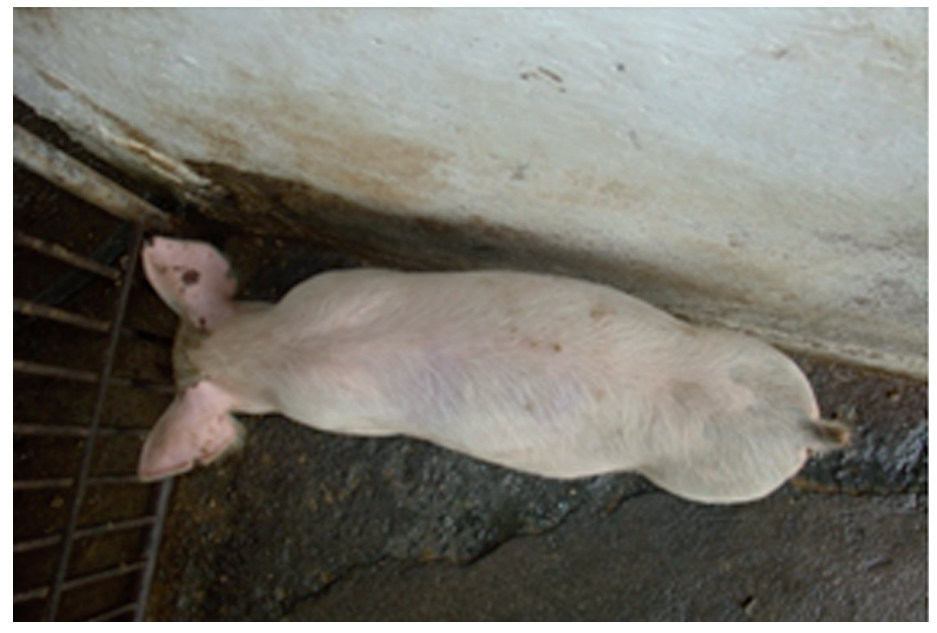

A3.7 Superior. Proteico + plátano (158 días)

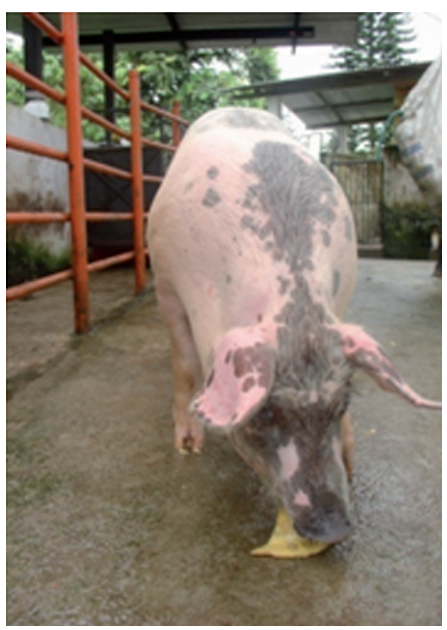

A3.6 Balanceado comercial (102 días)
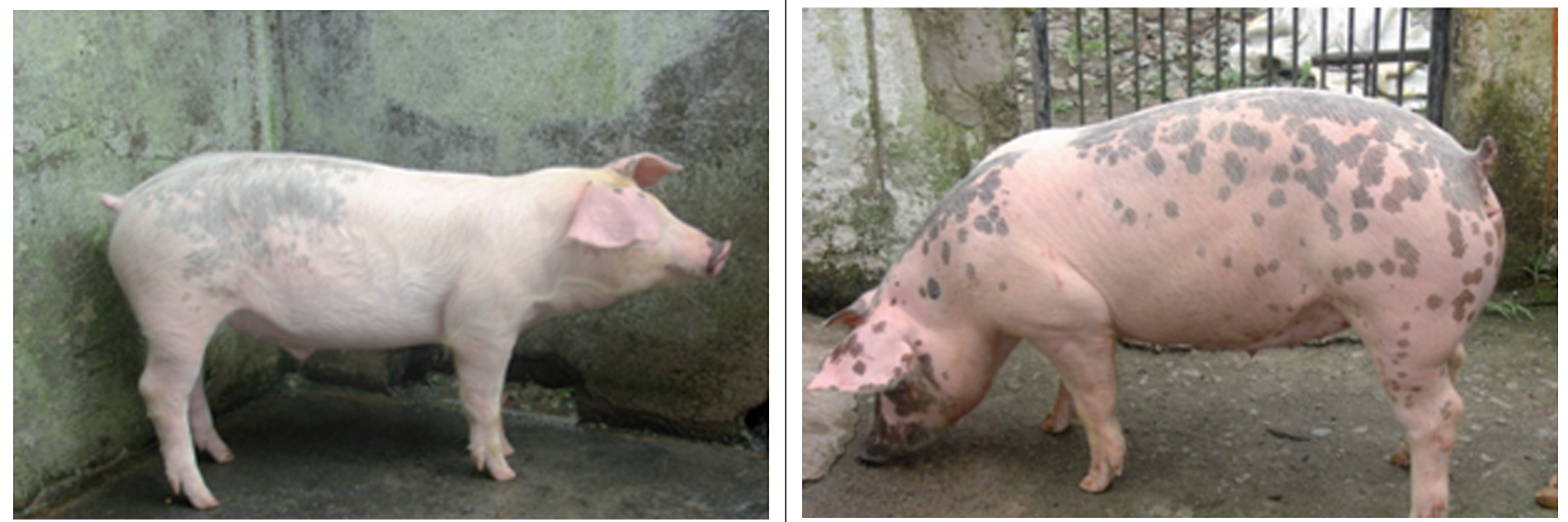

A3.8 Superior. Proteico + palmito (162 días)
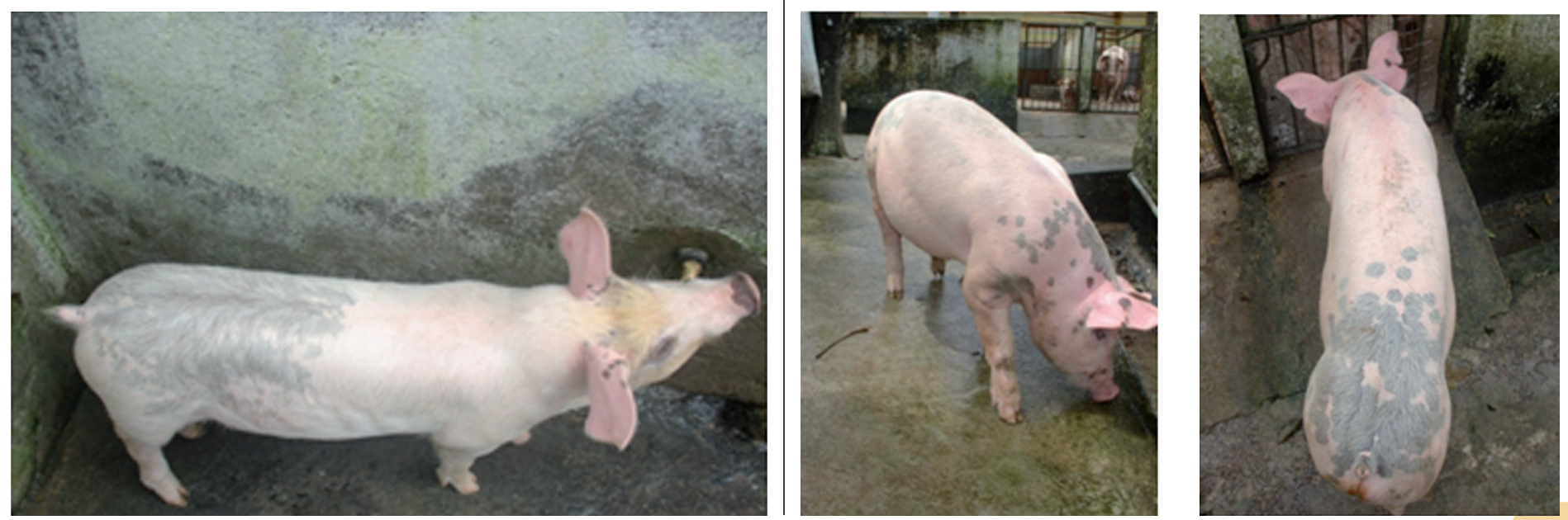

Tsafiquie 
A3.9 Balanceado comercial (149 días)
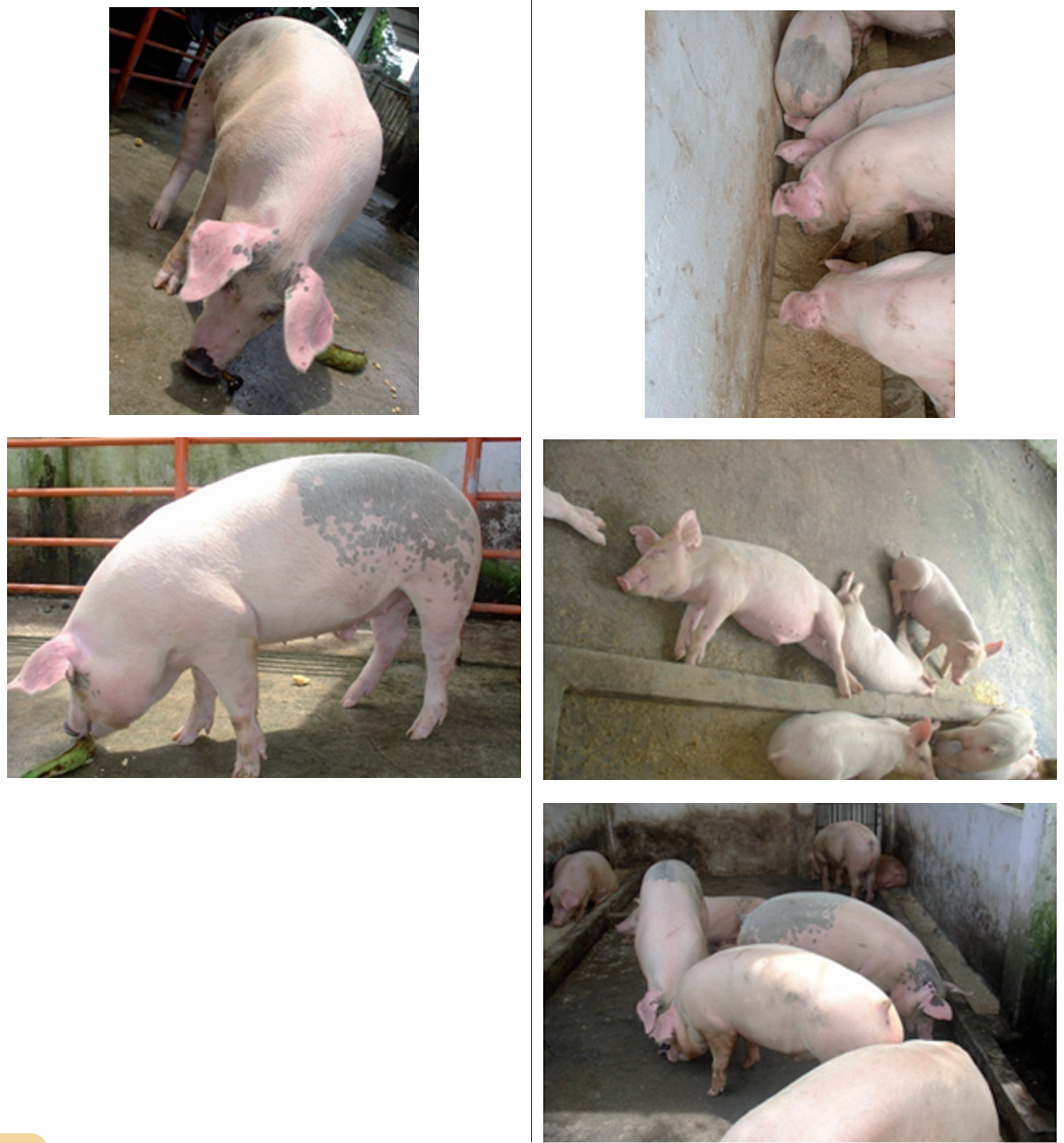

Tsafiquiew 
A3.11 Pesaje de los cerdos
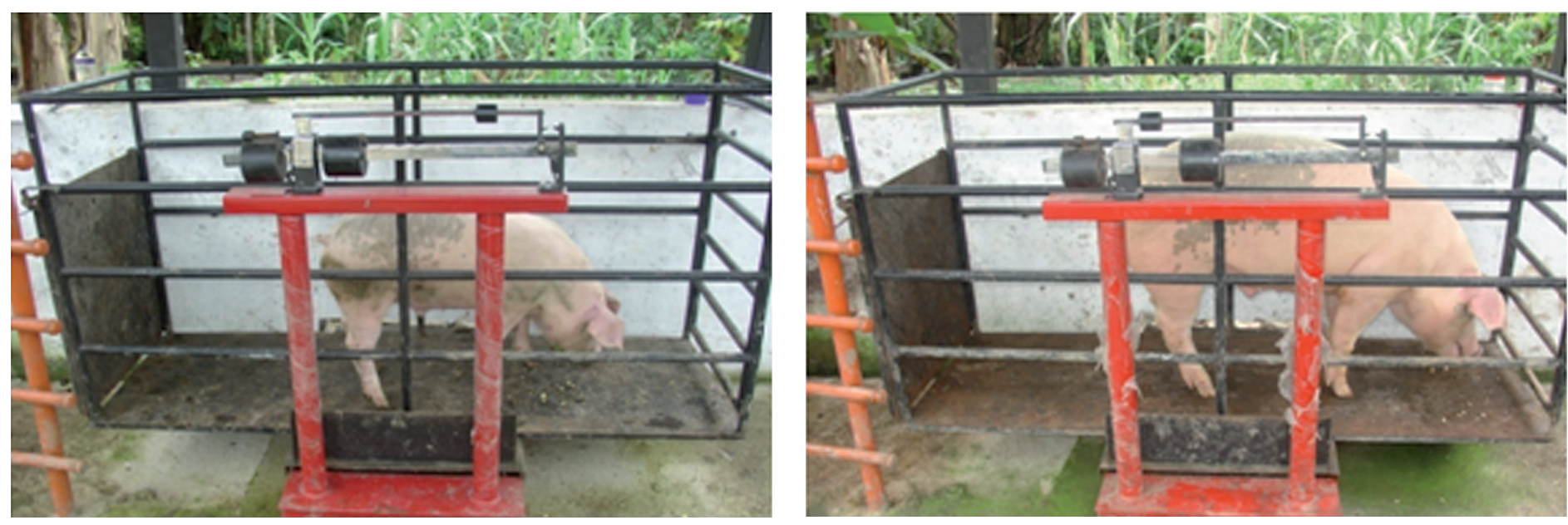

Anexo 6. Cerda alimentándose (Tratamiento plátano).

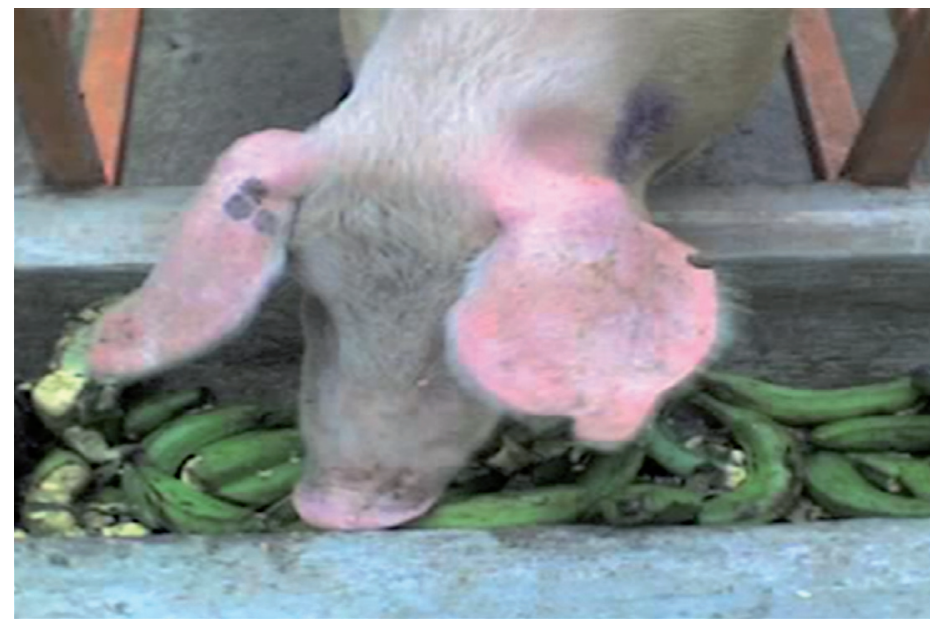

Anexo 8.Estructura metálica para alimentar individualmente a las cerdas.

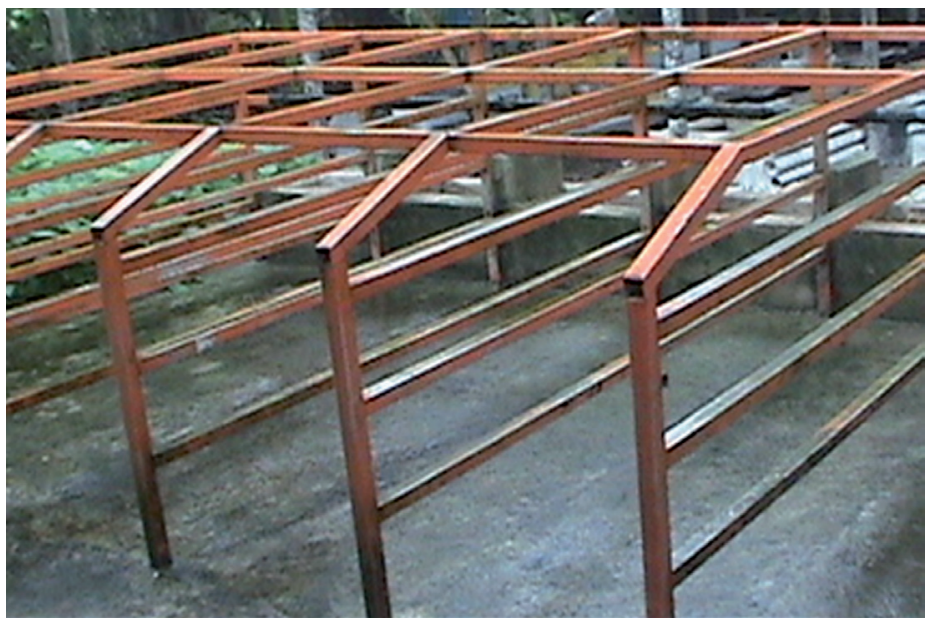

Anexo 7. Cerdas alimentándose (Tratamiento Palmito).

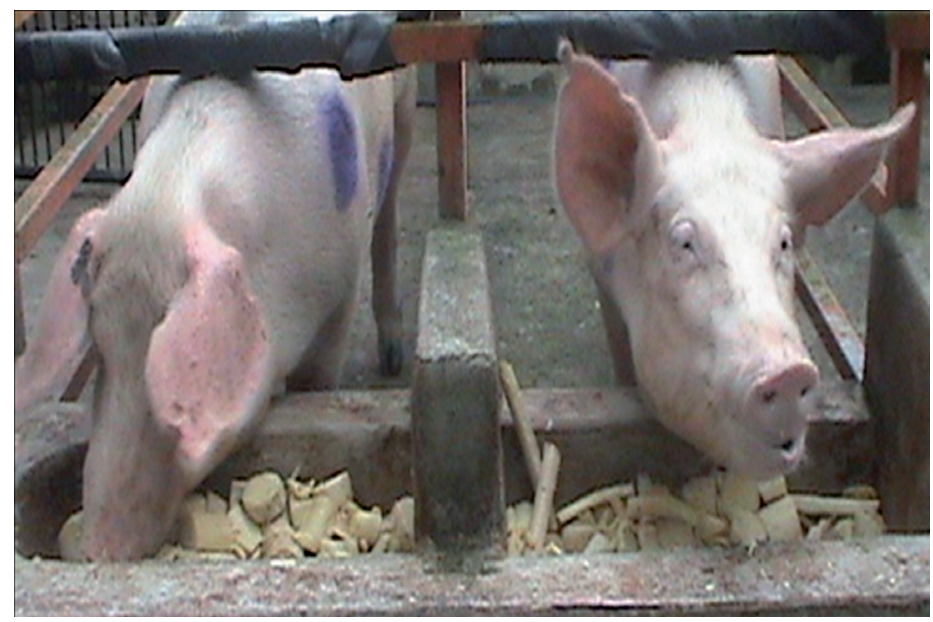

Anexo 9. Tipos de alimentos frescos para cerdas (Tratamiento Palmito).

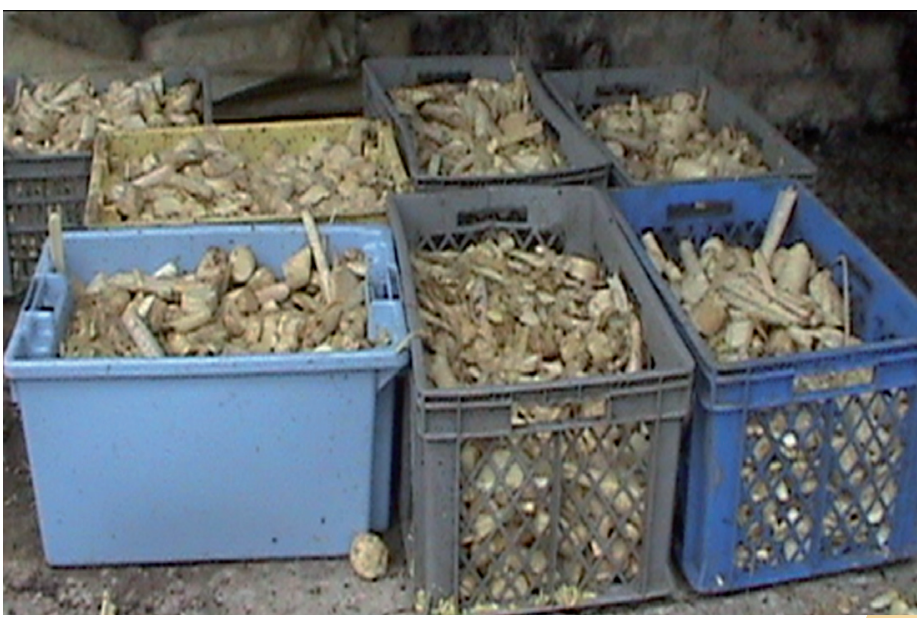

Tsafiquim 
Anexo 10. Tipos de alimentos frescos para cerdas (Tratamiento Plátano).
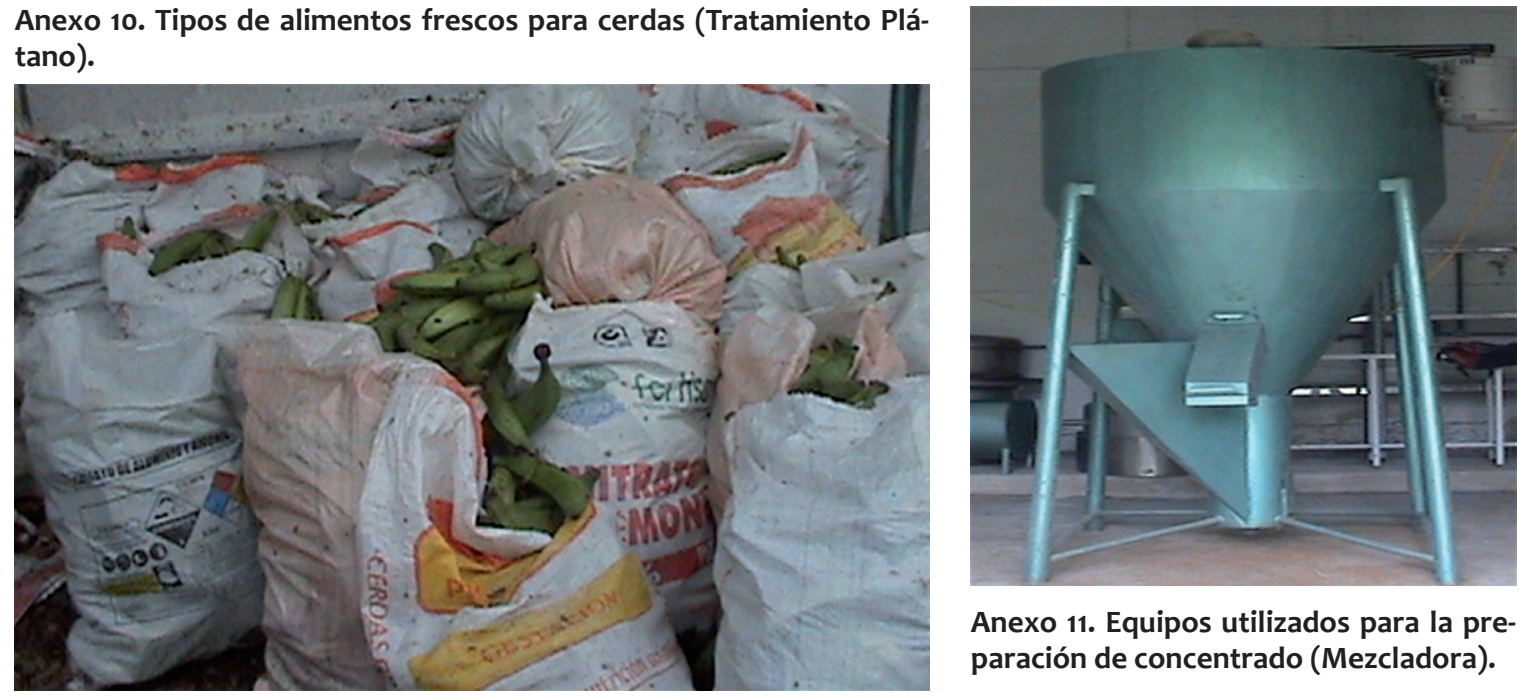

Anexo 11. Equipos utilizados para la preparación de concentrado (Mezcladora).
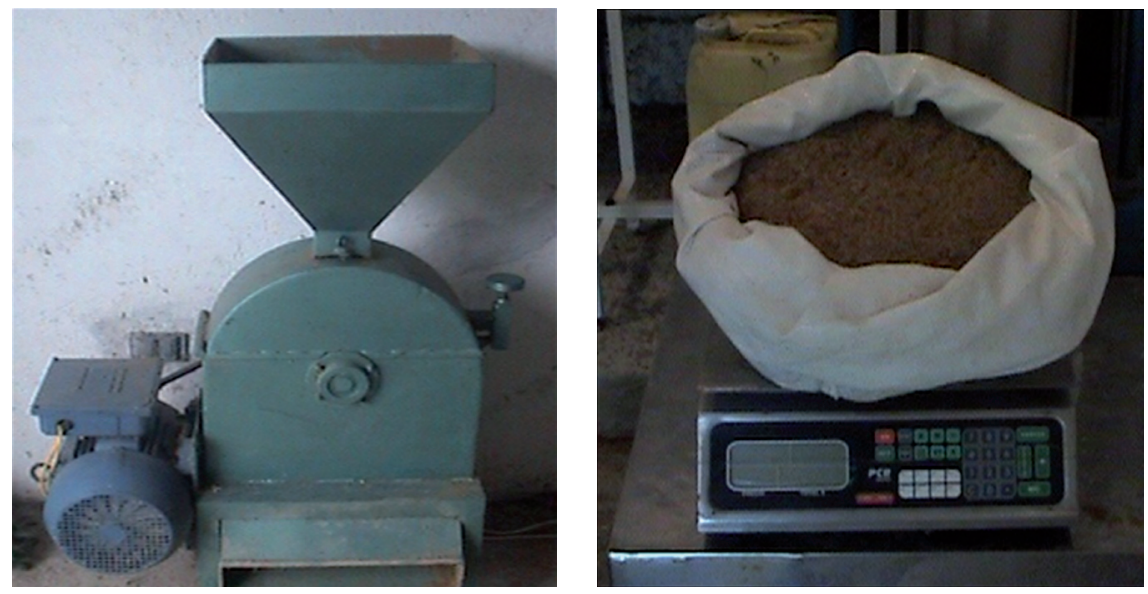

Anexo 12. Equipos utilizados para la preparación de concentrado (Moledora).

Anexo 13. Equipos utilizados para la preparación de concentrado (Balanza).
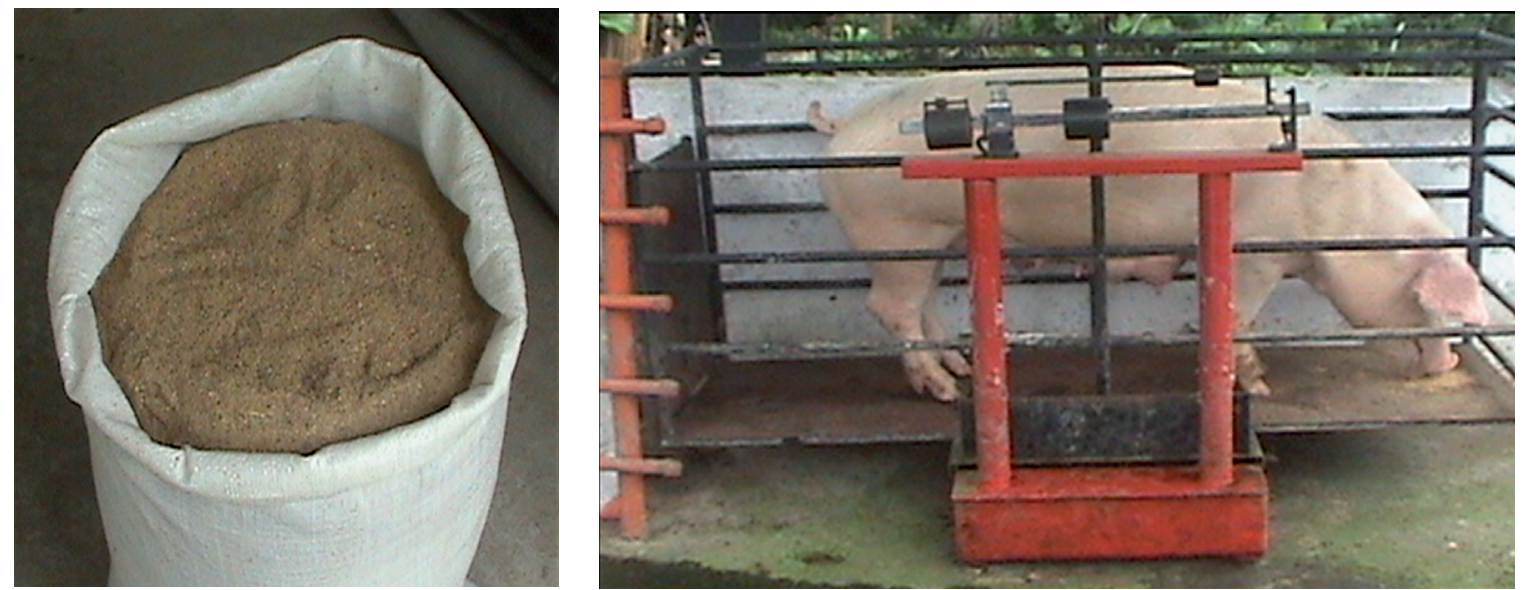

Anexo 14. Concentrado listo para ser utilizado en la alimentación de cerdas.

Anexo 15. Pesaje de la cerda en la báscula. 


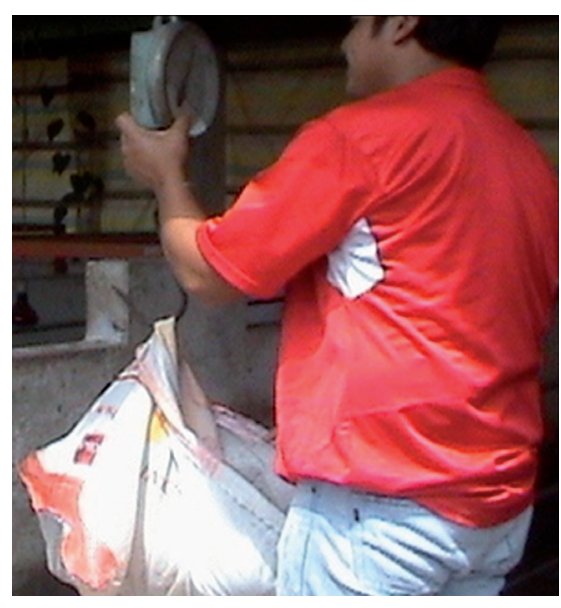

Anexo 16. Pesaje de lechones en balanza.

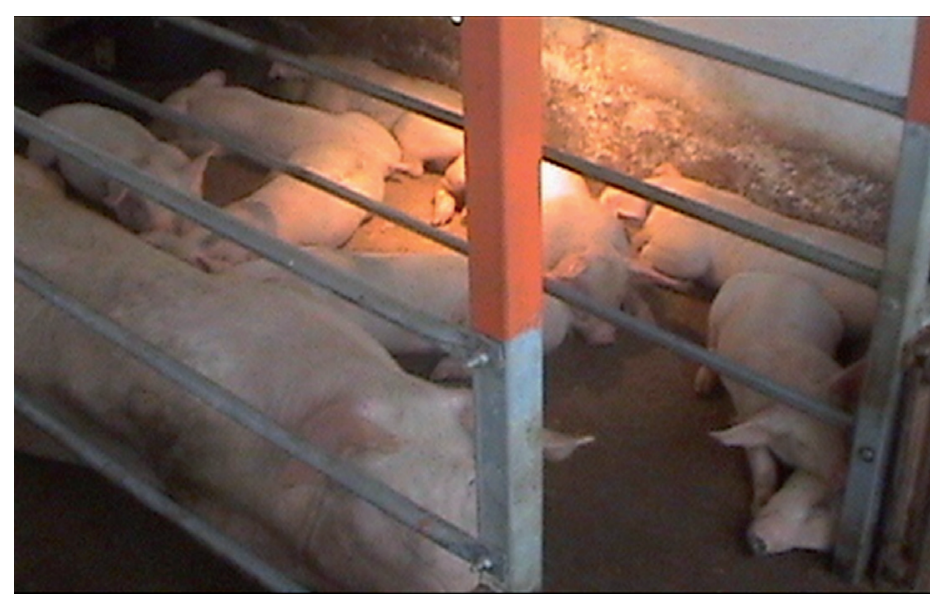

Anexo 18. Cerda y su camada, descansado en jaula paridera

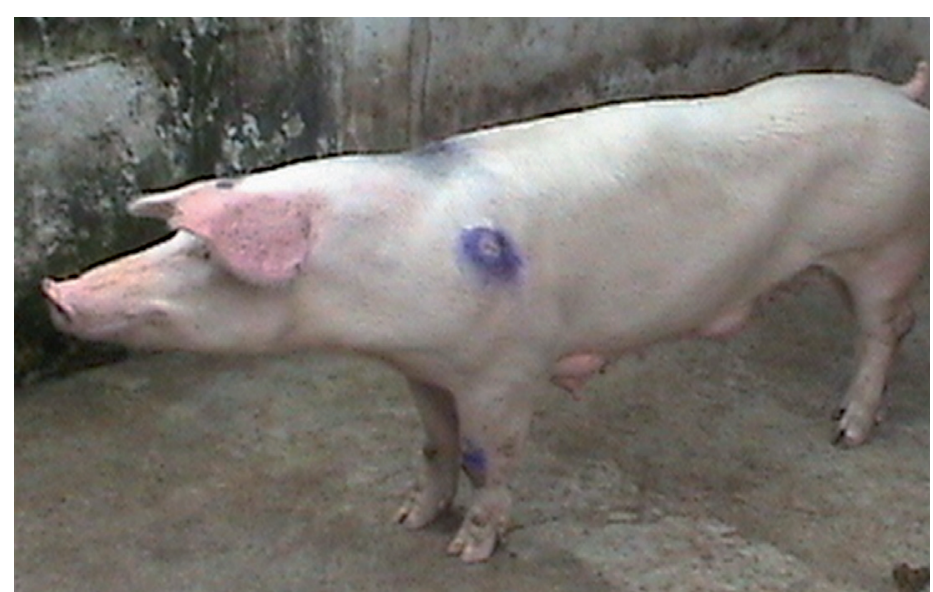

Anexo 20. Cerdas destetadas a los 45 días (Tratamiento Palmito)

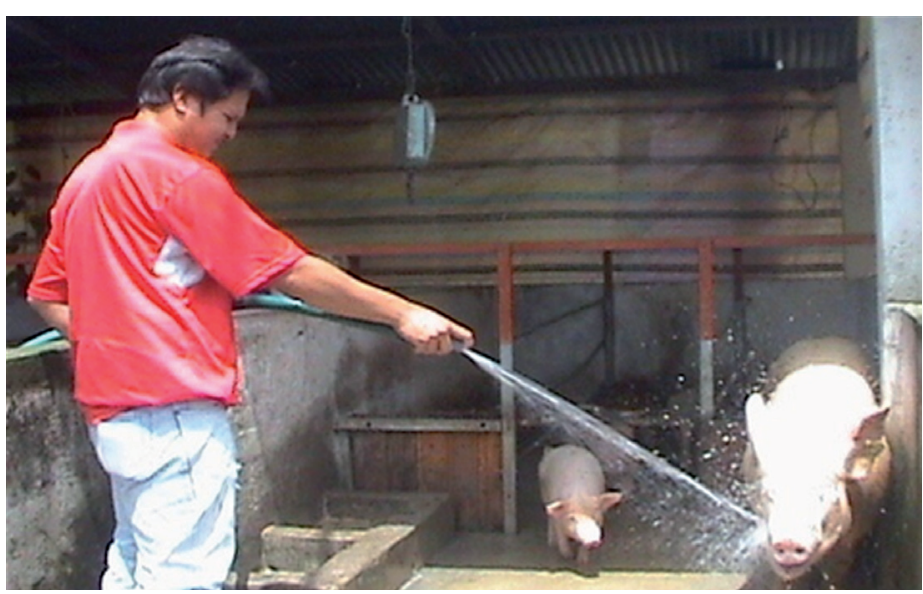

Anexo 17. Limpieza de corrales.

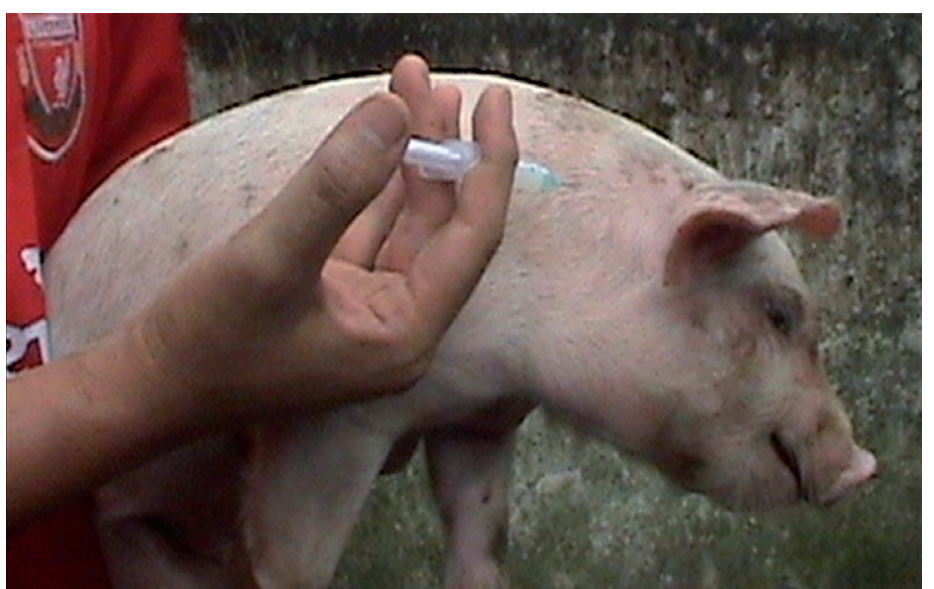

Anexo 19. Aplicación de vacunas en lechones

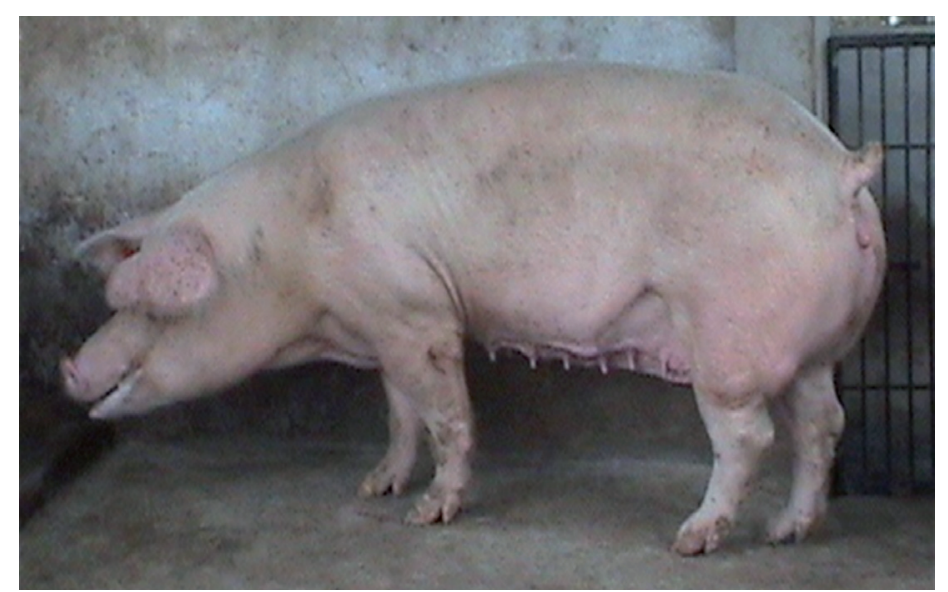

Anexo 21. Cerdas destetadas a los 45 días (Tratamiento Testigo) 175

Tsafiqui=an= 


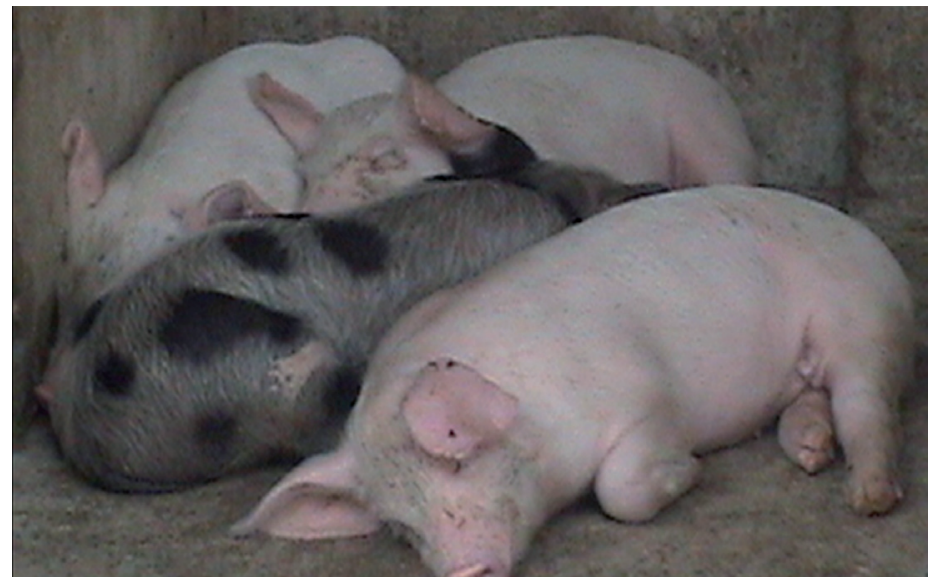

Anexo 22. Lechones destetados a los 45 días de edad 